OPEN ACCESS

UWS Academic Portal

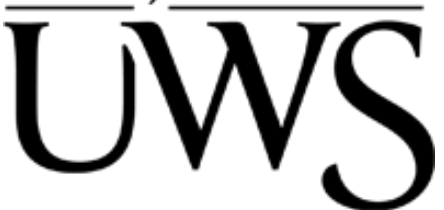

\title{
Experimental and numerical thermo-mechanical analysis of welding in a lined pipe
}

Obeid, Obeid; Alfano , Giulio; Bahai, Hamid; Jouhara, Hussam

Published in:

Journal of Manufacturing Processes

DOI:

10.1016/j.jmapro.2018.04.009

Published: 30/04/2018

Document Version

Peer reviewed version

Link to publication on the UWS Academic Portal

Citation for published version (APA):

Obeid, O., Alfano, G., Bahai, H., \& Jouhara, H. (2018). Experimental and numerical thermo-mechanical analysis of welding in a lined pipe. Journal of Manufacturing Processes, 32, 857-872.

https://doi.org/10.1016/j.jmapro.2018.04.009

\section{General rights}

Copyright and moral rights for the publications made accessible in the UWS Academic Portal are retained by the authors and/or other copyright owners and it is a condition of accessing publications that users recognise and abide by the legal requirements associated with these rights.

Take down policy

If you believe that this document breaches copyright please contact pure@uws.ac.uk providing details, and we will remove access to the work immediately and investigate your claim. 


\title{
Experimental and Numerical Thermo-Mechanical Analysis of Welding in a Lined Pipe
}

\author{
Obeid Obeid $^{1, a}$, Giulio Alfano ${ }^{1, b}$, Hamid Bahai ${ }^{1, c}$, Hussam Jouhara ${ }^{1, d}$ \\ ${ }^{1}$ College of Engineering, Design and Physical Sciences, Brunel University, UB8 3PH \\ Uxbridge, UK \\ aobeid.obeid@brunel.ac.uk, biulio.alfano@brunel.ac.uk, ${ }^{\mathrm{c}}$ hamid.bahai@brunel.ac.uk, \\ dhussam.jouhara@brunel.ac.uk
}

\begin{abstract}
Experimental tests of multi-pass lined pipe welding are reported and a computational procedure for the determination of the history of temperature, strains and residual stresses is presented in this paper and validated against the experimental test results. The effect of the manufacturing process of the lined pipe on the thermo-mechanical analysis has been investigated. A 3-D FE model using ABAQUS has been developed to simulate a circumferential single-pass weld overlay (lap-weld) and two-pass girth welding (butt-weld). Thermal history and strain fields have been recorded during welding using thermocouples and high temperature strain gauges, respectively. Residual stresses have been measured using residual stress gauges, deep-hole drilling technique and the X-ray diffraction technique along the outer and inner surfaces of the lined pipe. The welding test has been repeated twice to assess the accuracy of thermal and mechanical measurements. Overall, very good correlation has been observed between the experimental and numerical results.
\end{abstract}

Keywords: Lined pipe; Weld overlay; Girth welding; Thermal history; Strain; Residual stress

\section{Introduction}

Lined pipe welding is a complex process requiring two sequential welds. First, a weld overlay is used to seal the ends of the liner with the outer pipe. Consequently, no gap is formed between the liner and the backing steel [1, 2]. A girth welding is then executed to join two adjacent specimens of the formed pipe. The integrity assessment and estimate of life expectancy of the lined pipe require consideration of the thermal fields and residual stresses induced by welding. Experimental testing of lined pipes can be extremely time consuming and expensive, which makes computational modelling an effective alternative approach [3]. 
It has been over 25 years since Karlsson and Josefson [4] first proposed a full threedimensional thermal and mechanical study of the circumferential butt welding in a conventional (single-layer) pipe. Their C-Mn single-pass model using the finite-element (FE) code ADINAT/ADINA was experimentally validated by other similar work [5-7]. Using a similar type of non-linear analysis and the FE code ABAQUS, Brickstad and Josefson [8] numerically simulated a series of multi-pass girth-butt-welded stainless steel joints.

Over the last decade or so, significant developments in FE codes gave a high flexibility in predicting the thermal history and residual stresses in butt-welded steel pipes. Deng and Murakawa [9] developed 3D and 2D FE models in ABAQUS to analyse the temperature history and residual stresses resulting from a multi-pass girth weld for SUS304 stainless steel joints. Their results of the 3D model were in very good agreement with experimental measurements. Zhao et al. [10] developed a FE model of the butt-welding of two dissimilar pipes, one made of austenitic stainless steel (S30432) and the other one made of martensitic carbon steel (T92), using the FE code ABAQUS. Thermo-mechanical behaviour, the effect of heat input and welding pass number on the residual stress distributions were discussed in that study. The numerical results show that a decrease in the heat input leads to a reduction in the residual stresses in the S30432 steel side more than in the T92 steel side. Huang et al. [11] investigated the effect of hardening, annealing and melting on residual stresses produced in laser welded stainless sheets. The findings show that residual stresses increase in case the strain hardening is considered whilst the annealing and melting effect is neglected. Recently, multilayer additive manufacturing using laser deposition has been considered one of the new developments in thermo-mechanical field related to both welding and 3D printing [12]. Mukherjee et al. [13] developed a 3D thermal, fluid flow and mechanical model to calculate transient thermal and residual stress fields during material deposition, Inconel 718 and Ti$6 \mathrm{Al}-4 \mathrm{~V}$. The findings point out that reducing the thickness of each fabricated layer and doubling the heat input can reduce the residual stresses by $30 \%$ and $20 \%$, respectively.

The thermal and mechanical response of a lined pipe during welding depends on several factors including the material properties, heat input, welding pool geometry, boundary conditions, welding sequence and the manufacturing method. There are no articles in the literature which have specifically focussed on the testing or simulation of lined pipe welding, probably due to the complexity of the sequence of weld overlay and girth welding. In some related work, Deng et al. [14] tried to validate simulations of the welding of two dissimilar pipes, one made of a low alloy steel and the other made of an austenitic stainless steel. 
However, some discrepancies between the numerical and the experimental results were found because the weld cladding layer under the low alloy steel joint was not taken into account. As a consequence of the lined pipe welding limitation, Obeid et al. [15-17] presented a new procedure to simulate a typical lined pipe process including the weld overlay and girth welding. Furthermore, a sensitive analysis to determine the influence of the cooling time between weld overlay and girth welding and of the welding speed has been conducted thermally and mechanically [15]. However, the effect of the manufacturing procedure for lined pipes on the residual stresses during and after lined pipe welding has not been investigated yet.

Therefore, in this study, a three-dimensional thermo-mechanical FE model is developed using ABAQUS to study the thermal and mechanical behaviour induced by the weld overlay and two passes of girth welding for a lined pipe. The pipe specimens have been manufactured by using a pre-heat treatment procedure, known as tight fit pipe (TFP), to insert the liner inside the C-Mn pipe. In the numerical simulations, one case study (case A, or reference case) has not taken into account the TFP. Another case (case AH) has been modelled to examine the influence of pre-heat treatment on the stress/strain during and after lined pipe welding.

The 3D model presented is validated by comparing the numerical results with those from experimental tests conducted by the authors. In particular, the predicted temperature values were compared with those measured by thermocouples, and the predicted strains and stresses were compared with those measured using high temperature strain gauges, residual stress gauges and X-ray diffraction.

\section{Manufacturing process}

\subsection{Description of the lined pipe and welding parameters}

In the present work, the specimen of lined pipe sketched in Fig. 1 is manufactured from two adjacent pipes. The outer pipe is seamless and made of carbon-manganese C-Mn low carbon steel equivalent to E235 AISI 10305-1. The inner pipe is made of austenitic stainless steel Cr$\mathrm{Ni}$, AISI 304, which is well suited to be used in cryogenic applications without the ductility being affected [18]. The nominal chemical compositions of both materials are given in Table 1. The lined pipe specimen has an outer diameter of $114.3 \mathrm{~mm}$ and a wall thickness of 7.85 $\mathrm{mm}$, of which $6.35 \mathrm{~mm}$ is the outer pipe thickness and $1.5 \mathrm{~mm}$ is the thickness of inner pipe. The welded lined pipe consists of two lined pipe specimens with the length of each $200 \mathrm{~mm}$. Wet cutting has been used to get the required length of each specimen. 


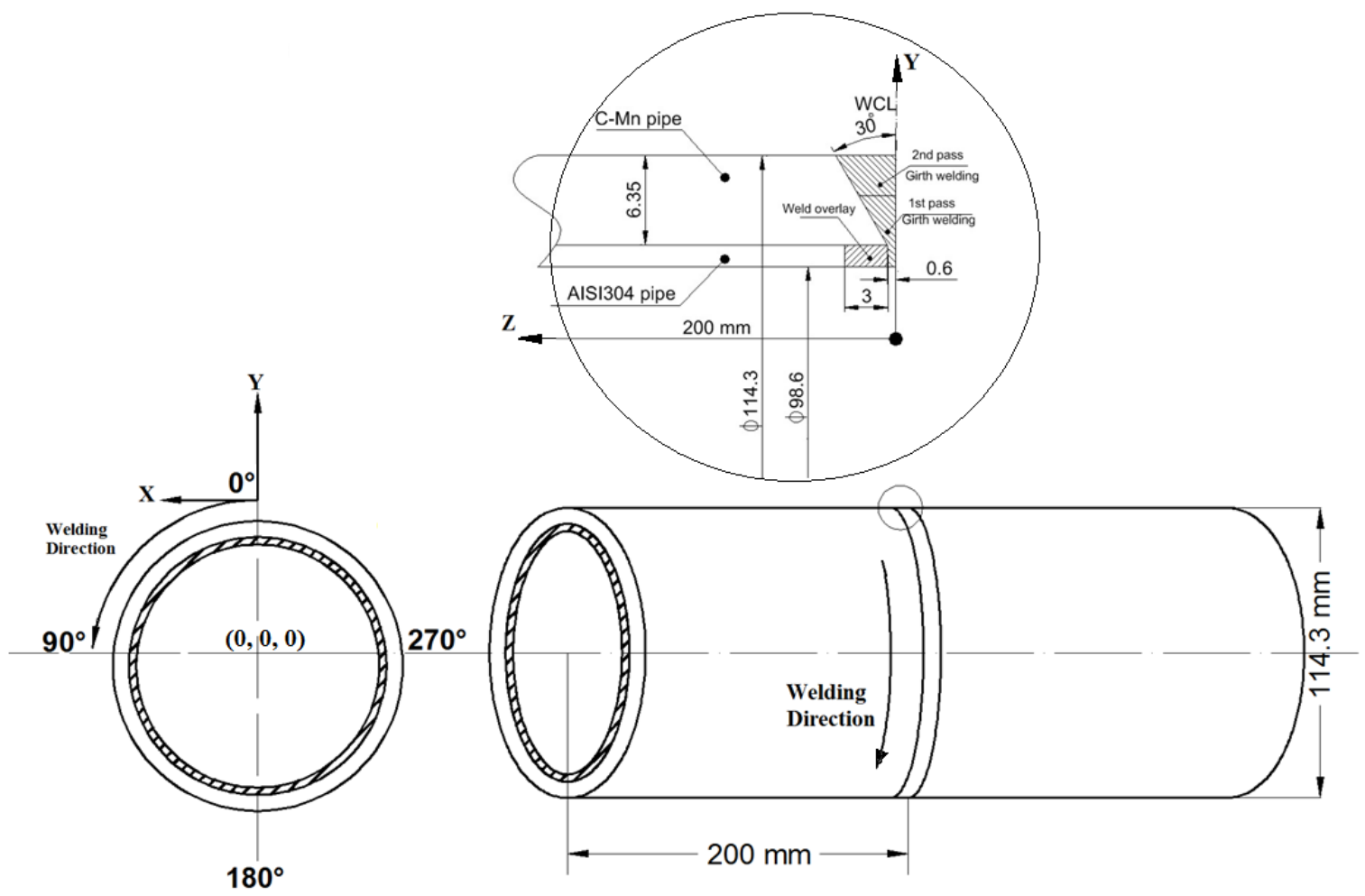

Fig. 1 Schematic sketches of the welded lined pipe with the welding direction for three passes, dimensions in $\mathrm{mm}$.

Table 1 Chemical composition of AISI 10305 (C-Mn) and AISI304.

\begin{tabular}{c|c|c|c|c|c|c|c|c}
\hline Steel grade & $\mathrm{C} \%$ & $\mathrm{Si} \%$ & $\mathrm{Mn} \%$ & $\mathrm{P} \%$ & $\mathrm{~S} \%$ & $\mathrm{Al} \%$ & $\mathrm{Cr} \%$ & $\mathrm{Ni} \%$ \\
\hline AISI 10305 & $\leq 0.17$ & $\leq 0.35$ & $\leq 1.2$ & $\leq 0.045$ & $\leq 0.045$ & $\geq 0.02$ & - & - \\
\hline AISI304 & $\leq 0.08$ & $\leq 1$ & $\leq 2$ & $\leq 0.045$ & $\leq 0.03$ & - & $18-20$ & $8-10.5$ \\
\hline
\end{tabular}

The TFP thermal manufacturing process is executed to insert the CRA liner inside the C-Mn pipe $[19,20]$. The process is explained in detail later in Section 3.1.1. After heat treatment, each lined pipe specimen is left to reach the ambient temperature naturally. The inner pipe (CRA liner) is cut to $3 \mathrm{~mm}$ from one end. Then, the outer pipe is chamfered with a $30^{\circ}$ angle from the same end using a CNC machine. Afterwards, two pieces of lined pipe are faced on the same alignment to be joined together, paying attention to avoid any misalignment of butt welds, which can lead to significant stress concentrations [21]. To weld the pipes, the onepass weld overlay is deposited at the cut end of the liner with ER308L stainless steel rod by Tungsten Inert Gas (TIG) welding. After that, two segments of lined pipe are assembled and fixed together by filling a two-pass girth welding in the V-groove formed outwardly between them. The girth welding is deposited with E70S2 mild steel rod using TIG welding. The final maximum inter-pass temperature between weld overlay and girth welding is normally around $100{ }^{\circ} \mathrm{C}$. 
During welding, the heat source is fixed and the two specimens of lined pipe are rotated with a uniform speed for each pass (one-pass weld overlay and two-pass girth welding). The weld overlay pass took 240 seconds to complete one revolution and then 270 seconds were used as inter-pass time between weld overlay and girth welding to allow natural cooling to the final maximum inter-pass temperature. The first and second passes of girth welding require 270 seconds each, too. Also, there is a second inter-pass time between the two girth welding passes, again of 270 seconds. After the second girth welding pass, the entire lined pipe took 3000 seconds to finally cool down naturally to ambient temperature. In all passes, welding begins at the central angle $\theta=0^{\circ}$ and then progresses through the anti-clockwise circumferential direction to complete one rotation and stop at the same starting point $\theta=$ $360^{\circ}$. Fig. 2 shows the lined pipe specimens during the welding overlay and girth welding.

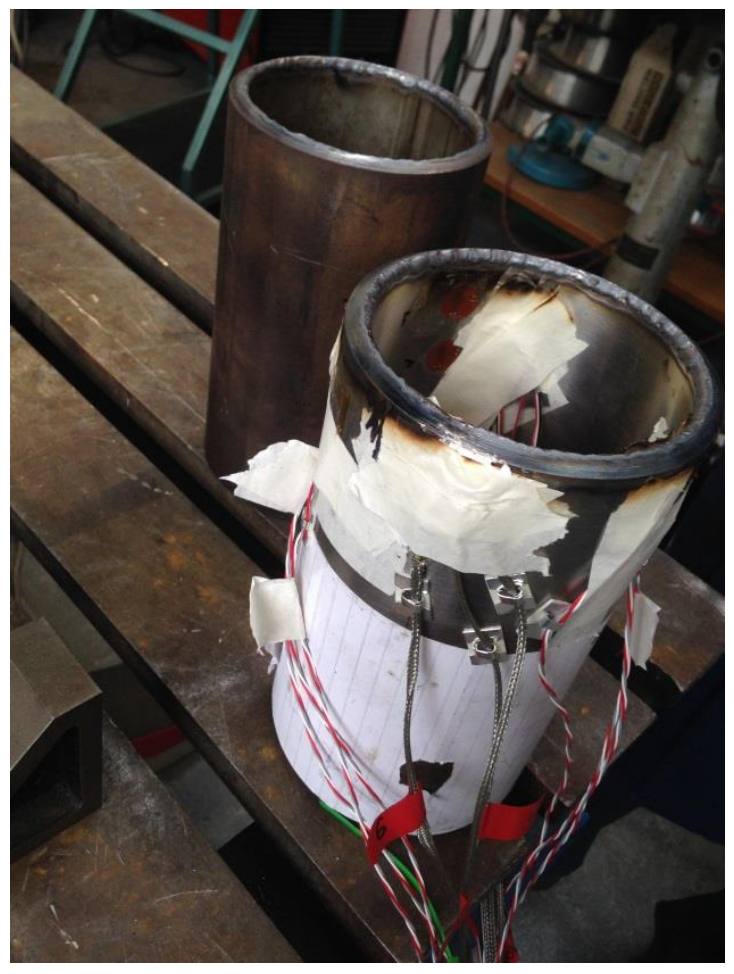

(a)

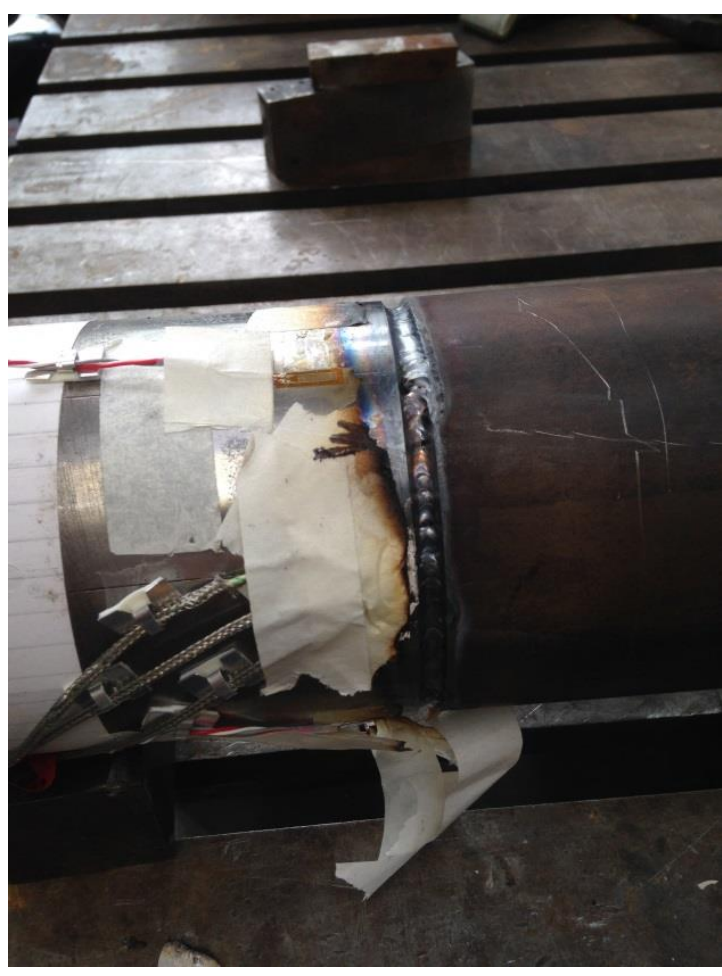

(b)

Fig. 2 Measuring the temperatures and strains during the (a) weld overlay and (b) girth welding In this work, the same thermal-mechanical material properties are used for both base and weld metals except the yield stress, because the weld material has higher yield stress in both C-Mn and AISI304 as shown in Table 2 and Table 3, respectively. 
Table 2 Thermo-mechanical properties of C-Mn [4].

\begin{tabular}{|c|c|c|c|c|c|c|c|c|c|c|}
\hline \multirow[t]{2}{*}{$\begin{array}{c}\text { Temperature } \\
\left({ }^{\circ} \mathrm{C}\right)\end{array}$} & \multirow[t]{2}{*}{$\begin{array}{l}\text { Density } \\
\left(\mathrm{kg} / \mathrm{m}^{3}\right)\end{array}$} & \multirow{2}{*}{$\begin{array}{c}\text { Specific } \\
\text { heat } \\
(\mathrm{J} / \mathrm{kg} \\
\left.{ }^{\circ} \mathrm{K}\right)\end{array}$} & \multirow[t]{2}{*}{$\begin{array}{l}\text { Conductivity } \\
\left(\mathrm{W} / \mathrm{m}^{\circ} \mathrm{K}\right)\end{array}$} & \multirow[t]{2}{*}{$\begin{array}{l}\text { Thermal } \\
\text { expansion } \\
\left(\times 10^{-5}{ }^{\circ} \mathrm{K}^{-}\right. \\
1)\end{array}$} & \multicolumn{2}{|c|}{$\begin{array}{l}\text { Yield stress } \\
(\mathrm{MPa})\end{array}$} & \multicolumn{2}{|c|}{$\begin{array}{c}\text { Yield stress at } \\
1 \% \text { hardening } \\
\text { (MPa) }\end{array}$} & \multirow[t]{2}{*}{$\begin{array}{l}\text { Young's } \\
\text { modulus } \\
(\mathrm{GPa})\end{array}$} & \multirow[t]{2}{*}{$\begin{array}{l}\text { Poisson's } \\
\text { ratio }\end{array}$} \\
\hline & & & & & Base & Weld & Base & Weld & & \\
\hline 0 & 7860 & 444 & 50 & 1.28 & 349 & 445 & 418 & 522 & 210 & 0.26 \\
\hline 100 & & 480 & 48.5 & 1.28 & 331 & 441 & 405 & 515 & 200 & 0.28 \\
\hline 200 & & 503 & 47.5 & 1.30 & 308 & 417 & 379 & 482 & 200 & 0.29 \\
\hline 300 & & 518 & 45 & 1.36 & 275 & 376 & 341 & 425 & 200 & 0.31 \\
\hline 400 & & 555 & 40 & 1.40 & 233 & 325 & 291 & 375 & 170 & 0.32 \\
\hline 600 & & 592 & 35 & 1.52 & 119 & 173 & 159 & 200 & 56 & 0.36 \\
\hline 800 & & 695 & 27.5 & 1.56 & 60 & 43 & 79 & 65 & 30 & 0.41 \\
\hline 1000 & & 700 & 27 & 1.56 & 13 & 14 & 20 & 32 & 10 & 0.42 \\
\hline 1200 & & 700 & 27.5 & 1.56 & 8 & 9 & 14 & 16 & 10 & 0.42 \\
\hline 1400 & & 700 & 35 & 1.56 & 8 & 9 & 13 & 16 & 10 & 0.42 \\
\hline 1600 & & 700 & 122.5 & 1.56 & 8 & 9 & 9.5 & 16 & 10 & 0.42 \\
\hline
\end{tabular}

Table 3 Thermo-mechanical properties of AISI304 [9, 18].

\begin{tabular}{|c|c|c|c|c|c|c|c|c|c|c|}
\hline \multirow[t]{2}{*}{$\begin{array}{c}\text { Temperature } \\
\left({ }^{\circ} \mathrm{C}\right)\end{array}$} & \multirow[t]{2}{*}{$\begin{array}{l}\text { Density } \\
\left(\mathrm{kg} / \mathrm{m}^{3}\right)\end{array}$} & \multirow[t]{2}{*}{$\begin{array}{c}\text { Specific } \\
\text { heat }(\mathrm{J} / \mathrm{kg} \\
\left.{ }^{\circ} \mathrm{K}\right)\end{array}$} & \multirow[t]{2}{*}{$\begin{array}{l}\text { Conductivi } \\
\text { ty (W/m } \\
\left.{ }^{\circ} \mathrm{K}\right)\end{array}$} & \multirow[t]{2}{*}{$\begin{array}{l}\text { Thermal } \\
\text { expansion } \\
\left(\times 10^{-5}{ }^{\circ} \mathrm{K}^{-1}\right)\end{array}$} & \multicolumn{2}{|c|}{$\begin{array}{l}\text { Yield stress } \\
\text { (MPa) }\end{array}$} & \multicolumn{2}{|c|}{$\begin{array}{c}\text { Yield stress } \\
\text { at } 1 \% \\
\text { hardening } \\
(\mathrm{MPa})\end{array}$} & \multirow[t]{2}{*}{$\begin{array}{c}\text { Young's } \\
\text { modulus } \\
(\mathrm{GPa})\end{array}$} & \multirow[t]{2}{*}{$\begin{array}{l}\text { Poisson's } \\
\text { ratio }\end{array}$} \\
\hline & & & & & Base & Weld & Base & Weld & & \\
\hline-200 & 7900 & 157 & 8.4 & 1.22 & 412 & - & 412 & - & 181 & 0.294 \\
\hline-100 & 7900 & 380 & 12.6 & 1.43 & 319 & - & 319 & - & 181 & 0.294 \\
\hline 0 & 7900 & 462 & 14.6 & 1.70 & 265 & 438 & 286 & 452 & 199 & 0.294 \\
\hline 100 & 7880 & 496 & 15.1 & 1.74 & 218 & 402 & 267 & 432 & 193 & 0.295 \\
\hline 200 & 7830 & 512 & 16.1 & 1.80 & 186 & 382 & 238 & 405 & 185 & 0.301 \\
\hline 300 & 7790 & 525 & 17.9 & 1.86 & 170 & 361 & 218 & 370 & 176 & 0.310 \\
\hline 400 & 7750 & 540 & 18.0 & 1.91 & 155 & 346 & 182 & 336 & 167 & 0.318 \\
\hline 600 & 7660 & 577 & 20.8 & 1.96 & 149 & 256 & 107 & 216 & 159 & 0.326 \\
\hline 800 & 7560 & 604 & 23.9 & 2.02 & 91 & 97 & 76 & 94 & 151 & 0.333 \\
\hline 1200 & 7370 & 676 & 32.2 & 2.07 & 25 & 28 & 25 & 29 & 60 & 0.339 \\
\hline 1300 & 7320 & 692 & 33.7 & 2.11 & 21 & 16 & 21 & 16 & 20 & 0.342 \\
\hline 1500 & 7320 & 700 & 120 & 2.16 & 10 & 12 & 10 & 12 & 10 & 0.388 \\
\hline
\end{tabular}

The latent heat for C-Mn steel is set to be $247 \mathrm{~kJ} / \mathrm{kg}$ between the solidus temperature of 1440 ${ }^{\circ} \mathrm{C}$ and the liquidus temperature of $1560{ }^{\circ} \mathrm{C}$. For stainless steel (AISI304), the latent heat is assumed to be $260 \mathrm{~kJ} / \mathrm{kg}$ between $1340{ }^{\circ} \mathrm{C}$ and $1390{ }^{\circ} \mathrm{C}$, solidus and liquidus temperatures respectively. Consequently, the melting point for $\mathrm{C}-\mathrm{Mn}$ is $1500{ }^{\circ} \mathrm{C}$ while it is $1365{ }^{\circ} \mathrm{C}$ for AISI304. The initial temperature of the lined pipe and the weld bead is set at room temperature.

To record the thermal history, type $\mathrm{K}$ thermocouples were placed at 6 axial locations with $180^{\circ}$ central angle. Three thermocouples were mounted on the outer surface (C-Mn pipe) and the others on the inner surface (AISI304) to record the thermal history at those locations during welding and cooling as shown in Fig. 3. 


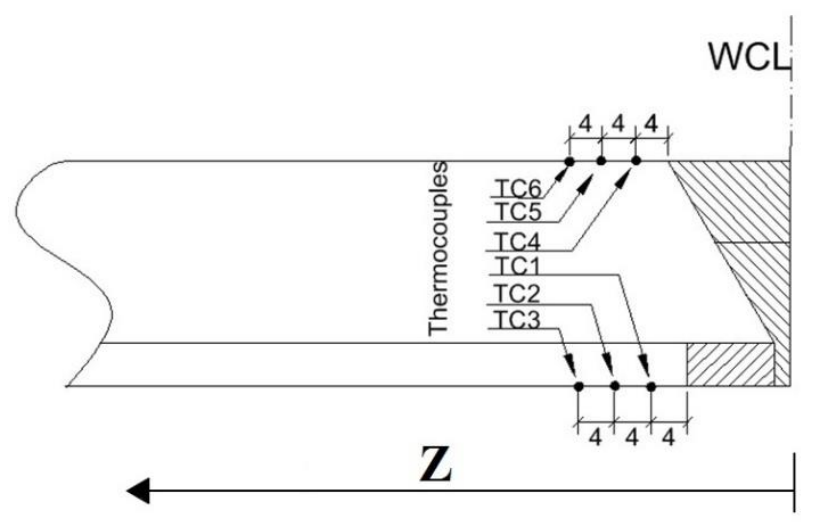

Fig. 3 Locations of thermocouples, dimensions in $\mathrm{mm}$.

To record the strain history during welding, the lined pipe was also equipped with 12 high temperature strain gauges to measure the axial and hoop strains on the outer and inner surfaces during the welding process and while cooling naturally to ambient temperature. In particular, 6 uniaxial ZFLA-11 strain gauges were mounted on the outer surface (C-Mn pipe). Three of them were mounted axially and the others were placed circumferentially. On the inner surface (liner), three biaxial strain gauge rosettes, ZFCAL-17, were also fixed to record the strain history axially and circumferentially. The precise locations of the inner and outer strain gauges are identified in Table 4.

Table 4 locations of strain gauges on the inner and outer surfaces for axial and hoop directions

\begin{tabular}{lllllll}
\hline Gauge (outer surface) & $\mathrm{A}$ & $\mathrm{B}$ & $\mathrm{C}$ & $\mathrm{D}$ & $\mathrm{E}$ & $\mathrm{F}$ \\
\hline Location $\left(\Theta^{\circ}, \mathrm{Z}(\mathrm{mm})\right)$ & $\left(45^{\circ}, 14\right)$ & $\left(36^{\circ}, 14\right)$ & $\left(270^{\circ}, 14\right)$ & $\left(261^{\circ}, 14\right)$ & $\left(135^{\circ}, 18\right)$ & $\left(126^{\circ}, 18\right)$ \\
Measured strain & Axial & Hoop & Axial & Hoop & Axial & Hoop \\
\hline Gauge (inner surface) & $\mathrm{G}$ & $\mathrm{H}$ & $\mathrm{I}$ & $\mathrm{J}$ & $\mathrm{K}$ & $\mathrm{L}$ \\
\hline Location $\left(\Theta^{\circ}, \mathrm{Z}(\mathrm{mm})\right)$ & $\left(45^{\circ}, 14\right)$ & $\left(45^{\circ}, 14\right)$ & $\left(270^{\circ}, 14\right)$ & $\left(270^{\circ}, 14\right)$ & $\left(135^{\circ}, 18\right)$ & $\left(135^{\circ}, 18\right)$ \\
Measured strain & Axial & Hoop & Axial & Hoop & Axial & Hoop \\
\hline
\end{tabular}

The thermal and mechanical experimental results were recorded every 0.001 second through LabVIEW software fitted with the data logger.

To record the residual stresses after welding, while cooling down to ambient temperature, residual stress gauges with three elements, FRS-2, were mounted on the inner surface (liner) and outer surface (C-Mn pipe). A reference hole with diameter and depth of $2 \mathrm{~mm}$ each was drilled vertically through the pipe thickness using a high speed milling machine as shown in Fig. 4. Also, the X-Ray diffraction technique has been used to double check the reliability of residual stress measurement. 


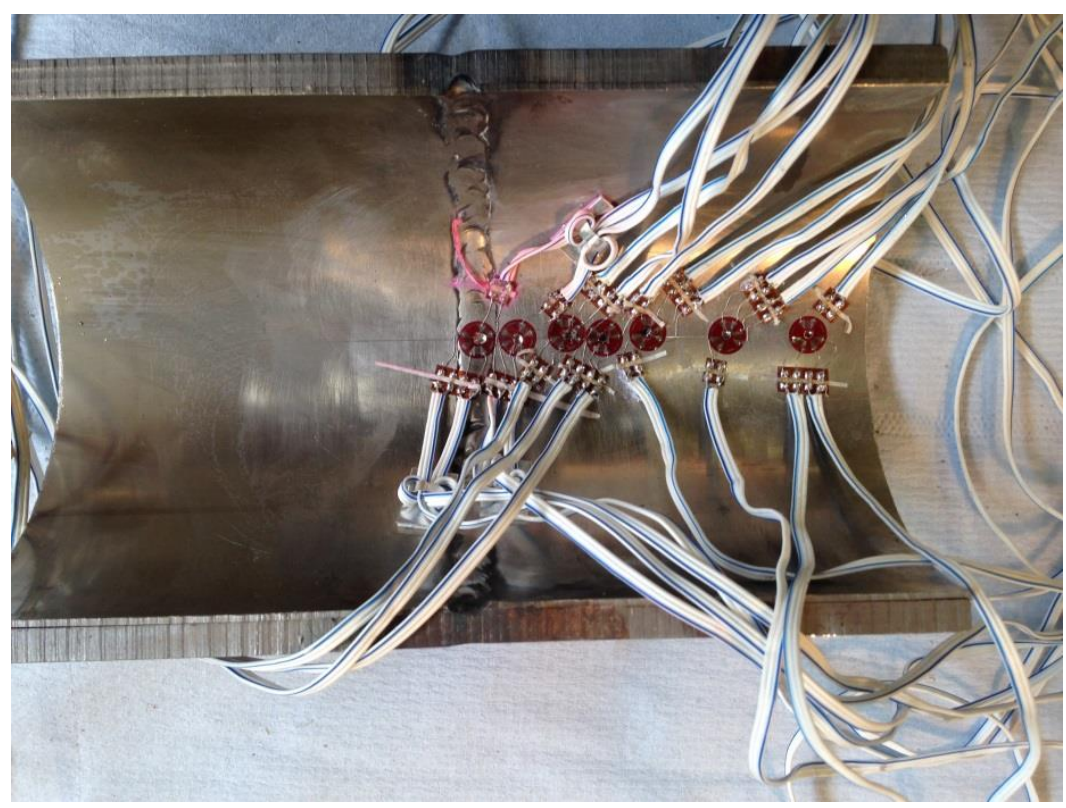

Fig. 4 Residual stress gauge rosette with three elements, FRS-2.

\section{Finite element modelling}

Only one-half of the lined pipe specimen was modelled due to the symmetry around the weld centreline WCL. The problem is modelled by uncoupled quasi-static thermo-elasto-plasticity equations. The element type in the thermal analysis is a continuum, three-dimensional 20node quadratic brick diffusive heat transfer element, named DC3D20 in ABAQUS. It has 20 degrees of freedom, which are the temperature values at each of its 20 nodes. The element type in the mechanical analysis is a continuum fully-integrated three-dimensional 20-noded element, named C3D20 in ABAQUS, with three translation degrees of freedom at each node, for a total of 60 degrees of freedom per element. The element birth technique is adopted in the FE models to simulate depositing the filler materials in the weld overlay and girth welding during the motion of the heat source [16]. Fig. 5 shows the mesh of the 3D FE model, which is the same for the thermal and mechanical analyses, so that the nodes and elements have the same numbers and arrangements in both simulations. The model is composed of 35220 nodes associated with 7380 elements. It can be seen there is a finer mesh in the fusion zone (FZ) and in the heat affected zone (HAZ) of the weld overlay for the inner pipe, and of the two-pass girth welding for the outer pipe, due to the high temperatures and their high gradients in these regions. The weld overlay, liner, girth welding and C-Mn pipe are coloured with red, light blue, yellow and green, respectively, as depicted in Fig. 5. 


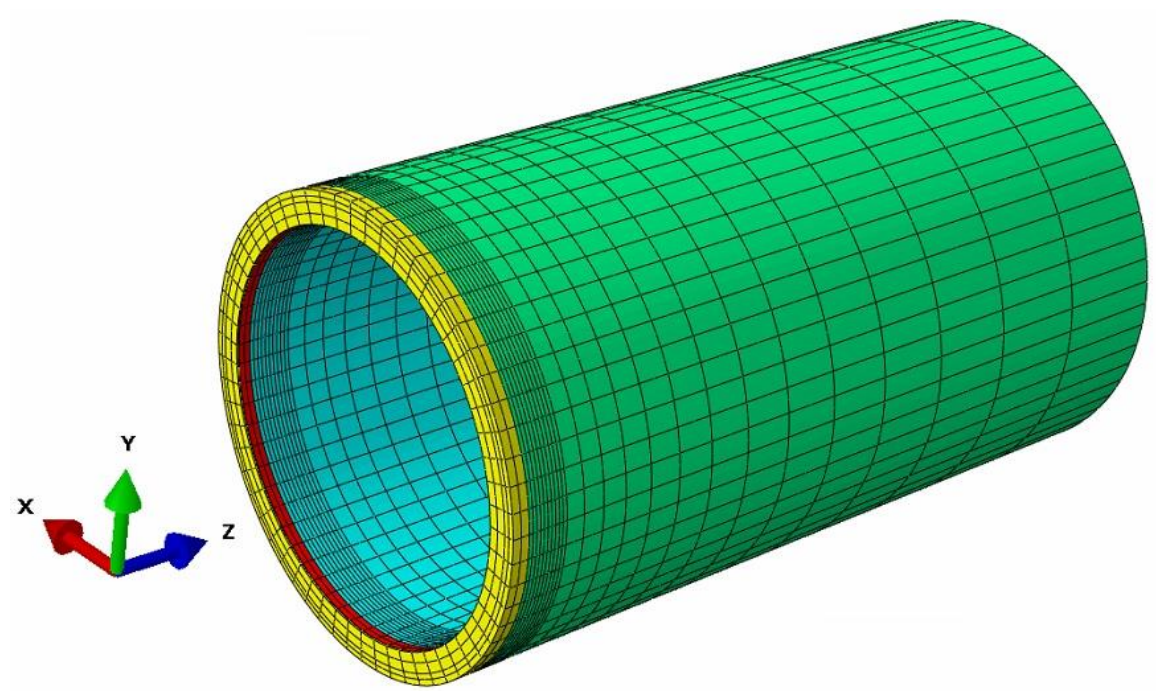

Fig. 5 3-D FE model

\subsection{Thermal Analysis}

\subsubsection{Pre-heat treatment}

As for the above discussion, a special heat treatment, known as tight fit pipe (TFP), was used to insert the liner (AISI304 pipe) inside the backing pipe (C-Mn pipe), and this generates initial residual stresses in the lined pipe before the welding operation is started. The TFP heat treatment process has been carried out according to the following steps:

(1) Heating up the whole C-Mn pipe gradually to $500{ }^{\circ} \mathrm{C}$ inside a furnace, to increase its dimensions because of thermal expansion.

(2) Cooling down the whole liner continuously using liquid nitrogen at $-200{ }^{\circ} \mathrm{C}$ inside a container, to reduce its dimension because of thermal shrinking.

(3) Lifting the outer pipe from the furnace and then putting it in a portable furnace, a socalled jacket heater, to keep the temperature close to $500{ }^{\circ} \mathrm{C}$ before the liner is inserted.

(4) Taking the liner away from the liquid nitrogen and then pushing it smoothly inside the CMn pipe, while the latter is still inside the jacket heater.

(5) Removing the jacket heater.

The TFP heat treatment has been simulated in the FE model by giving the initial state of temperature for the liner and C-Mn pipe as $-200{ }^{\circ} \mathrm{C}$ and $500{ }^{\circ} \mathrm{C}$, respectively.

After inserting the liner inside the C-Mn pipe, the lined pipe is naturally exposed to ambient air temperature for 7200 seconds after which the temperature of the whole lined pipe reached room temperature as shown in Fig. 6. 


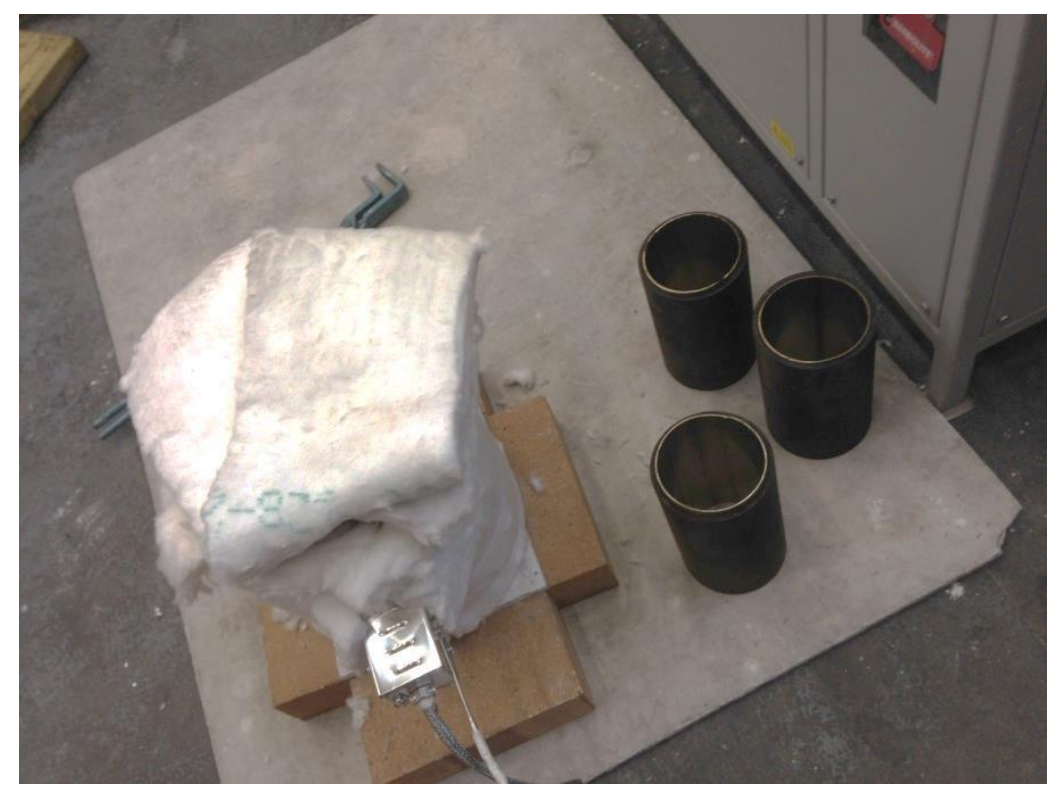

Fig. 6 Cooling down the lined pipe specimens to room temperature after TFP.

Throughout this time, the external surface of the C-Mn pipe is subjected to natural convection heat exchange with the atmosphere according to Newton's law, given as:

$$
q_{c}=-h_{c}\left(T_{c}-T_{a}\right)
$$

where $q_{c}$ is the heat loss from the C-Mn surface, $T_{c}$ is the surface temperature of the C-Mn pipe, $T_{a}$ is the ambient temperature, that is $20{ }^{\circ} \mathrm{C}$, and $h_{c}$ is the heat transfer coefficient between the surface of $\mathrm{C}-\mathrm{Mn}$ pipe and the atmosphere of room which is assumed to be constant and equal to $8 \mathrm{~W} / \mathrm{m}^{2} \mathrm{~K}$.

In a similar way, the AISI304 pipe is forcibly cooled down in liquid nitrogen $\left(-200{ }^{\circ} \mathrm{C}\right)$. After being slid inside the C-Mn pipe, it is heated naturally to room temperature. During this process, the convective heat exchange between the internal surface of the AISI304 inner pipe and the room atmosphere is also subject to Newton's law, expressed by:

$$
q_{s}=h_{s}\left(T_{s}-T_{a}\right)
$$

where $q_{s}$ is the heat gain by the AISI304 surface, $T_{s}$ is the surface temperature of the AISI304 pipe, $T_{a}$ is the ambient temperature, that is $20{ }^{\circ} \mathrm{C}$, and $h_{s}$ is the heat transfer coefficient between the surface of AISI304 pipe and the atmosphere of the room which is assumed to be constant, $5.7 \mathrm{~W} / \mathrm{m}^{2} \mathrm{~K}$.

\subsubsection{Temperatures during lined pipe welding}

A transient heat-transfer analysis during welding, in general, is governed by the classical energy balance equation and its derivative equations to evaluate the thermal history during 
welding. These equations have been discussed by Obeid et al. [15] whose investigations have included work on the numerical lined pipe welding. In this study, the welding process starts after TFP treatment is completed and the ends of the lined pipe are machined with the whole pipe at room temperature. During welding, the heat transfer from the pipe is a combination of radiation and convection. Radiation loss dominates in the weld zone and its vicinity where temperatures are near the melting point. Convective loss dominates away from the weld zone. In this work, the thermal boundary conditions are applied on all external surfaces of the lined pipe exposed to the environment. The total heat loss is a combination of radiation, $q_{\text {radiation }}$ and convection, $q_{\text {conviction }}$ losses given as follows:

$$
\begin{gathered}
q_{\text {convection }}=-h_{\text {convection }}\left(T_{\text {pipe }}-T_{a}\right) \\
q_{\text {radiation }}=-\sigma_{e m} \varepsilon_{\text {bol }}\left(T_{\text {pipe }}^{4}-T_{a}^{4}\right) \\
h_{\text {total }}=h_{\text {convection }}+\sigma_{\text {em }} \varepsilon_{\text {bol }}\left(T_{\text {pipe }}+T_{a}\right)\left(T_{\text {pipe }}^{2}+T_{a}^{2}\right)
\end{gathered}
$$

where $h_{\text {convection }}$ is the convective heat transfer coefficient, $T_{\text {pipe }}$ is the current temperature at the pipe surface, $T_{a}$ is the ambient temperature, which is $20{ }^{\circ} \mathrm{C}, \sigma_{e m}$ is the effective radiation emissivity, $\varepsilon_{b o l}$ is the Stefan-Boltzmann constant and $h_{\text {total }}$ is the total combined temperature-dependent heat-transfer coefficient.

As the lined pipe is composed of two different materials, each material is characterised by different coefficients governing heat transfer with the room atmosphere, as shown in Table 5.

Table 5 heat transfer parameters

\begin{tabular}{lll}
\hline Parameters & $\mathrm{C}-\mathrm{Mn}$ & AISI304 \\
\hline$h_{\text {convection }}\left(\mathrm{W} / \mathrm{m}^{2} \mathrm{~K}\right)$ & $8[15]$ & $5.7[15]$ \\
$\sigma_{\text {em }}$ & 0.51 & 0.75 \\
$\varepsilon_{\text {bol }}\left(\mathrm{W} / \mathrm{m}^{2} \mathrm{~K}^{4}\right)$ & $5.67 \times 10^{-8}$ & $5.67 \times 10^{-8}$ \\
\hline
\end{tabular}

A FILM user subroutine [22] has been coded in FORTRAN to implement in ABAQUS the above expression of the total heat-transfer coefficient, Eq. (5).

The heat input transmitted from the heat torch to the lined pipe and weld regions is modelled by a Gaussian distribution as a function of position and time in an ellipsoid (welding pool) with centre that is taken as $\left(x_{0}, y_{0}, z_{0}\right)[17]$ :

$$
q(x, y, z, t)=\frac{6 Q \sqrt{3}}{a b c \pi \sqrt{\pi}} e^{-3\left(x-\left(R \sin \theta+x_{0}\right)\right)^{2} / a^{2}} e^{-3\left(y-\left(R \cos \theta+y_{0}\right)\right)^{2} / b^{2}} e^{-3\left(z-z_{0}\right)^{2} / c^{2}}
$$

where $Q=I V \mu$ is the energy input rate which is given by the product of the current $I$, voltage $V$ and the weld efficiency $\mu, R$ is the radial distance of the heat torch centre from the pipe 
axis, $\theta$ is the angle from the start/stop point (where $\theta=0^{\circ}$ ). Parameters $a, b$ and $c$ are the semi-axes of the ellipsoidal welding pool in directions, $x, y$ and $z$, respectively, as shown in Fig. 7. To obtain uniformly distributed heat along the welding direction, the parameters $a, b$ and $c$ must be carefully adjusted. In particular, the parameters $a$ and $c$ should be greater than or equal to the length and width of welding elements set (weld bead), respectively, whilst the parameter $b$, the controlling parameter, should adjust the uniformity of heat distribution for all identical circumferential elements sets accordingly. Furthermore, the parameter $b$, the depth of welding pool, should allow welding materials to flow into welding grooves where all nodes should reach the melting points accordingly. Equation (6) has been implemented in ABAQUS by coding the DFLUX user-subroutine. The position of the weld torch is calculated first in DFLUX according to the welding time $t$. Thereafter, the power density $q$ is computed at each integration point.

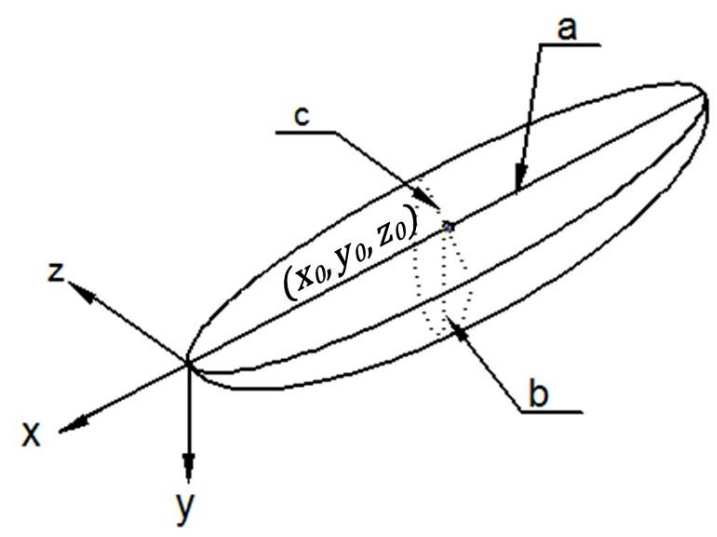

Fig. 7 Ellipsoidal welding pool with semi-axes $a, b$ and $c$.

The numerical values for the variables used in the power density distribution in Eq. (6) are illustrated in Table 6 for each welding material.

Table 6 Heat source and welding parameters.

\begin{tabular}{lclll}
\hline Parameter & Symbol & Weld overlay & $\begin{array}{l}1^{\text {st }} \text { pass } \\
\text { girth welding }\end{array}$ & $\begin{array}{l}2^{\text {nd }} \text { pass } \\
\text { girth welding }\end{array}$ \\
\hline Half-length of welding pool (mm) & $a$ & 4.9 & 6.2 & 6.2 \\
Depth of welding pool (mm) & $b$ & 1.5 & 2.62 & 2.85 \\
Half-width of welding pool (mm) & $c$ & 4.9 & 5.57 & 5.66 \\
Welding current (A) & $I$ & 242 & 484 & 515 \\
Voltage (V) & $V$ & 10 & 10 & 10 \\
Welding speed (mm/s) & $v$ & 1.3 & 1.26 & 1.33 \\
Welding efficiency & $\mu$ & $70 \%$ & $70 \%$ & $70 \%$ \\
\hline
\end{tabular}

To take into consideration the effect of a moving heat source with element birth, the one-pass weld overlay and two-pass girth welding are each meshed circumferentially into 60 identical elements. The length of each bead is assumed to be equal to one element block in the 
circumferential direction. Consequently, the appropriate time step for each pass in the FE model is recognised as given in Eq. (7):

$$
\text { Step time }=\frac{\text { Total pass time }(s)}{\text { Number of circumferential elements along the WCL }}
$$

where the total time of weld overlay pass, first girth welding pass and the second welding pass are 240, 270 and 270 seconds associated with 60 elements around WCL, respectively.

\subsection{Structural analysis}

The FE mesh used in the thermal analysis is employed in the mechanical analysis apart from the boundary conditions and element type. Here, the nodal temperature histories read from the thermal output file are considered thermal loads for each increment in the mechanical simulation. At each structural step, an automatic time increment is executed and geometrical nonlinear effects (large deformation) have been incorporated in the FE model.

During the lined pipe welding process, the effects of volumetric change and the transformation plasticity (the change in the yield stress value) because of metallurgical martensitic transformation (phase transformation) have been neglected in this work because the volume dilation and the reduction in the yield stress value due to the phase transformation are small $[23,24]$. Therefore, the increment of the total strain, $d \varepsilon_{i j}$, has been broken down into three components as follows:

$$
d \varepsilon_{i j}=d \varepsilon_{i j}^{e}+d \varepsilon_{i j}^{p}+d \varepsilon_{i j}^{t h}
$$

where $d \varepsilon_{i j}^{e}, d \varepsilon_{i j}^{p}$ and $d \varepsilon_{i j}^{t h}$ are the elastic, plastic and thermal strain increments, respectively. The elastic behaviour is defined by the isotropic Hook's law. For the plastic behaviour, the Von Mises yield criterion has been used with an associated flow rule. The Young's modulus, Poisson ratios and yield stresses used are reported in Tables 2 and 3 as a function of temperature. All material nodes are under the influence of multiple thermal loading and unloading, so that the Bauschinger effect should be considered. As a result, a linear kinematic hardening rule has been assumed for both materials, C-Mn and AISI304, with the hardening parameter obtained from the temperature-dependent yield stress as plotted in Tables 2 and 3, when the plastic strain of C-Mn and AISI304 is equal to $1 \%[25,26]$. The thermal strain is the result of expansion and contraction of the lined pipe materials and it is governed by the temperature-dependant thermal expansion coefficients reported in Tables 2 and 3. 
In the mechanical analysis, initial boundary conditions are performed to just prevent lined pipe motion. Due to the symmetry of model, the symmetry plane is fixed in the longitudinal direction, the Z-direction. On the lined pipe end, lateral and transversal restrictions are applied at the lined pipe end in the $\mathrm{X}$ and Y-directions as illustrated by arrows in Fig. 8.

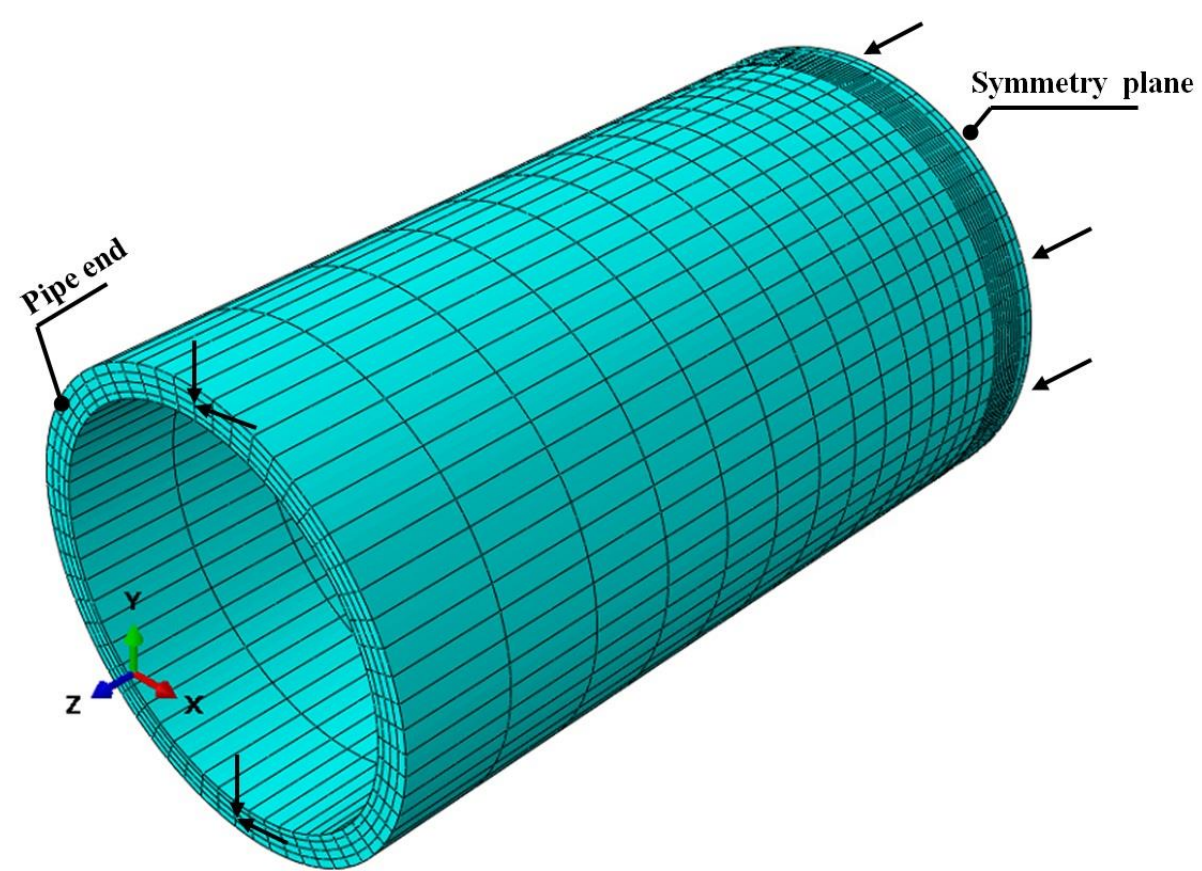

Fig. 8 Mechanical boundary conditions.

\section{Results and discussions}

\subsection{Temperature response}

Both cases, $\mathrm{A}$ and $\mathrm{AH}$, have the same thermal history during welding because, after the heat treatment, the temperature reaches room temperature before increasing throughout the welding process. It is noted that temperatures in the fusion zones of weld overlay and twopass girth welding are higher than the melting points, 1500 and $1365{ }^{\circ} \mathrm{C}$ for $\mathrm{C}-\mathrm{Mn}$ and AISI304, respectively, as they should be.

Fig. 9 also shows the numerically computed temperature distributions at $90^{\circ}, 180^{\circ}$ and $270^{\circ}$ central angle during weld overlay where the girth welding has not been deposited yet. As anticipated, the maximum temperature is achieved at the welding pool centre of weld overlay, $1634^{\circ} \mathrm{C}$. From this figure, it can be seen that the thermal histories of weld overlay pool centres at three circumferential locations, $90^{\circ}, 180^{\circ}$ and 270 , have very similar shapes and magnitudes during the transient thermal cycle. 

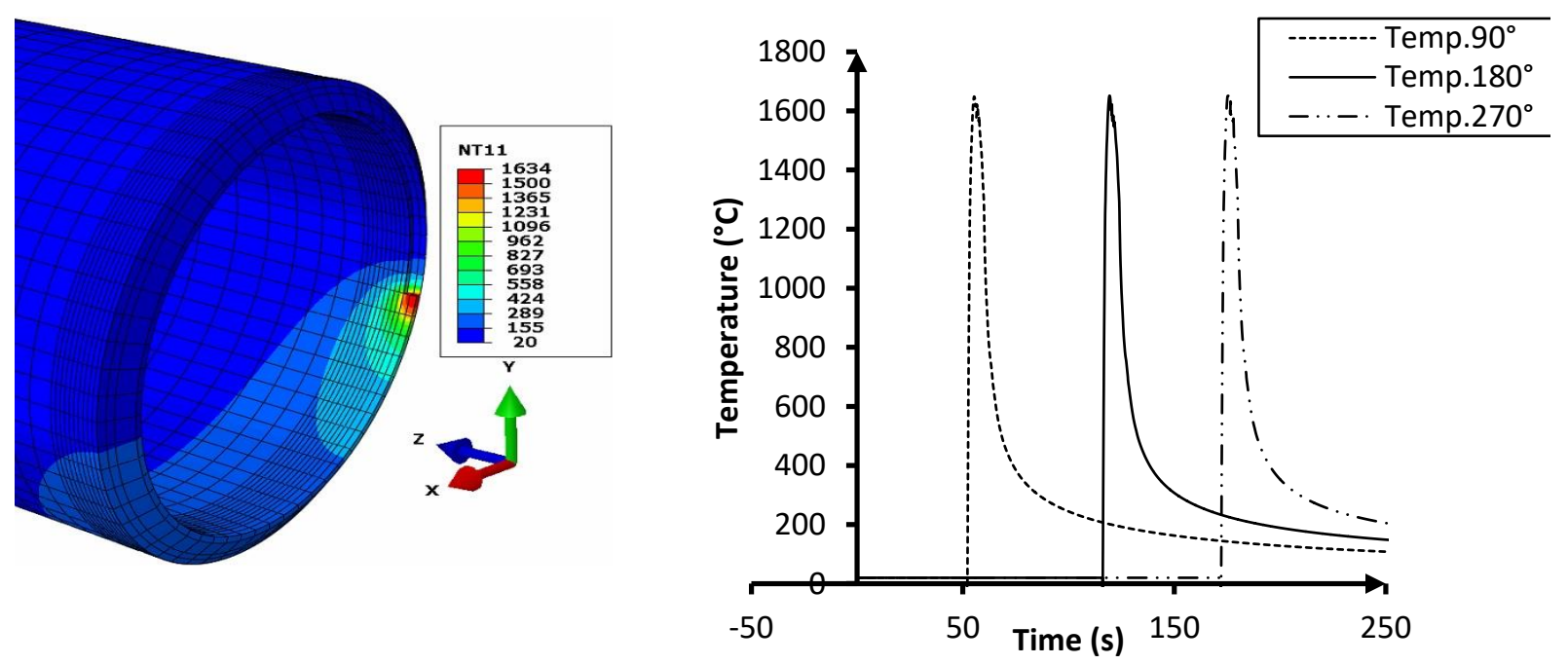

Fig. 9 The thermal history of weld overlay centre at $90^{\circ}, 180^{\circ}$ and $270^{\circ}$ central angle.

Likewise, the numerically computed temperature histories at the second pass of girth welding also have identical distributions circumferentially around the mid-plane (symmetric line) at three locations, $90^{\circ}, 180^{\circ}$ and $270^{\circ}$. The three curves reach the same peak temperature, $2076^{\circ} \mathrm{C}$, and it can be seen that weld overlay and first-pass girth welding and three quarters of the second-pass girth welding have been laid down in their grooves as shown in Fig. 10.
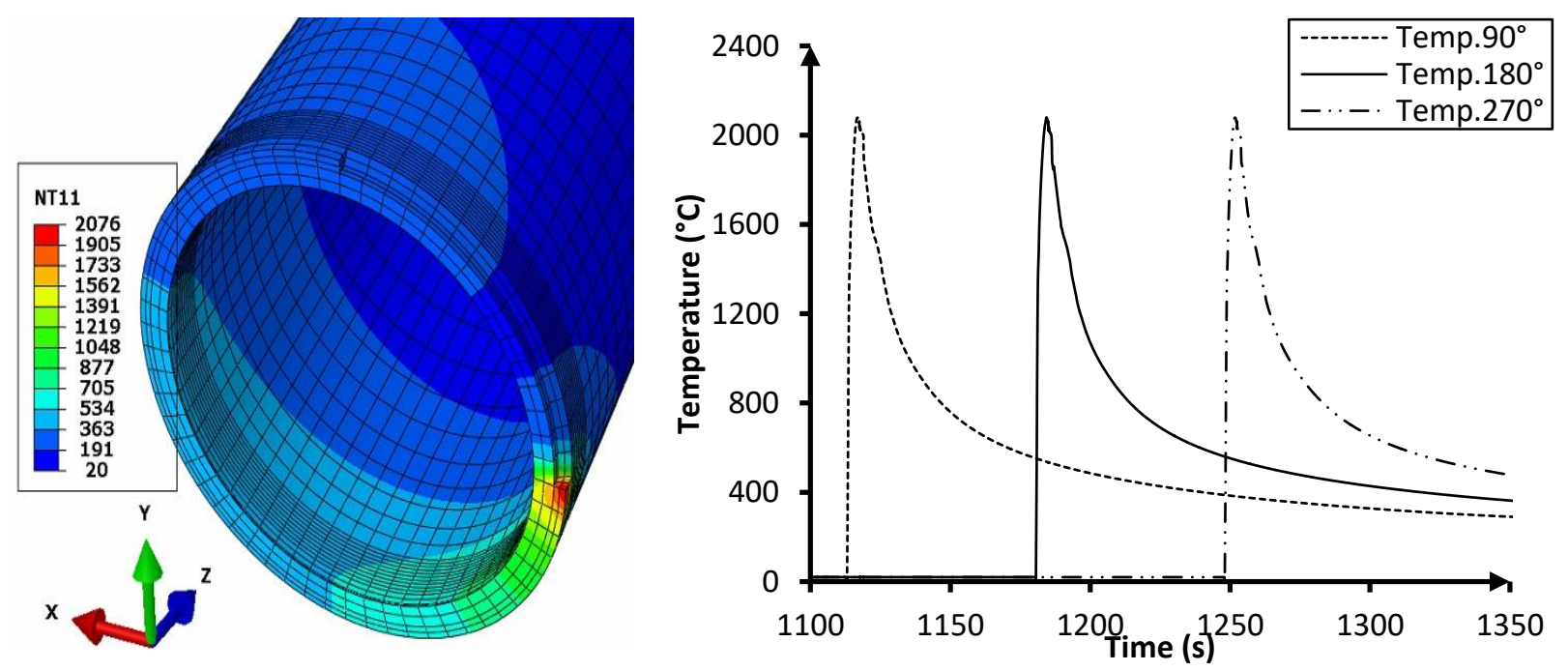

Fig. 10 The thermal history of second pass centre of girth welding at $90^{\circ}, 180^{\circ}$ and $270^{\circ}$ central angle.

Fig. 11 shows the thermal history of two points at $180^{\circ}$ circumferential angle on the inner and outer surfaces, including the pre-heat treatment. The inner point is located at the border between the weld overlay FZ and the HAZ of base material, AISI304. The outer point is located between the FZ of the second pass girth welding and the HAZ of the backing steel. 


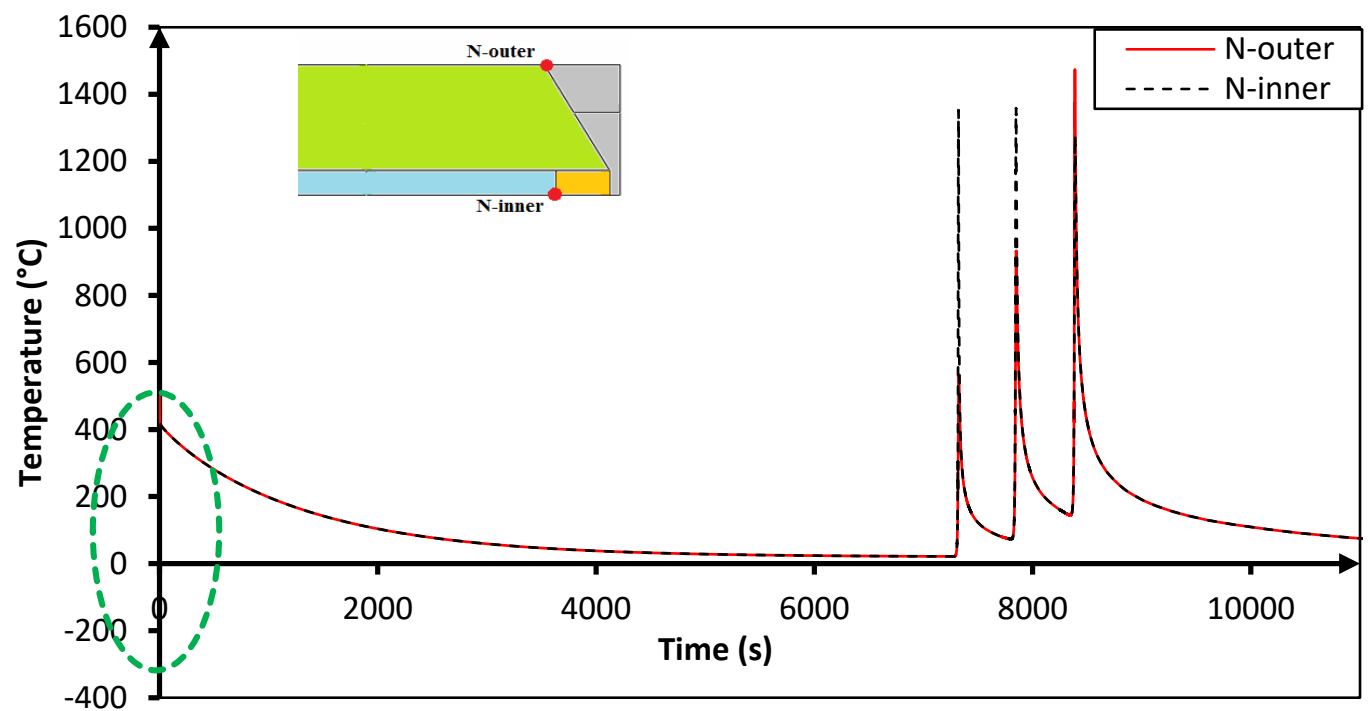

(a)

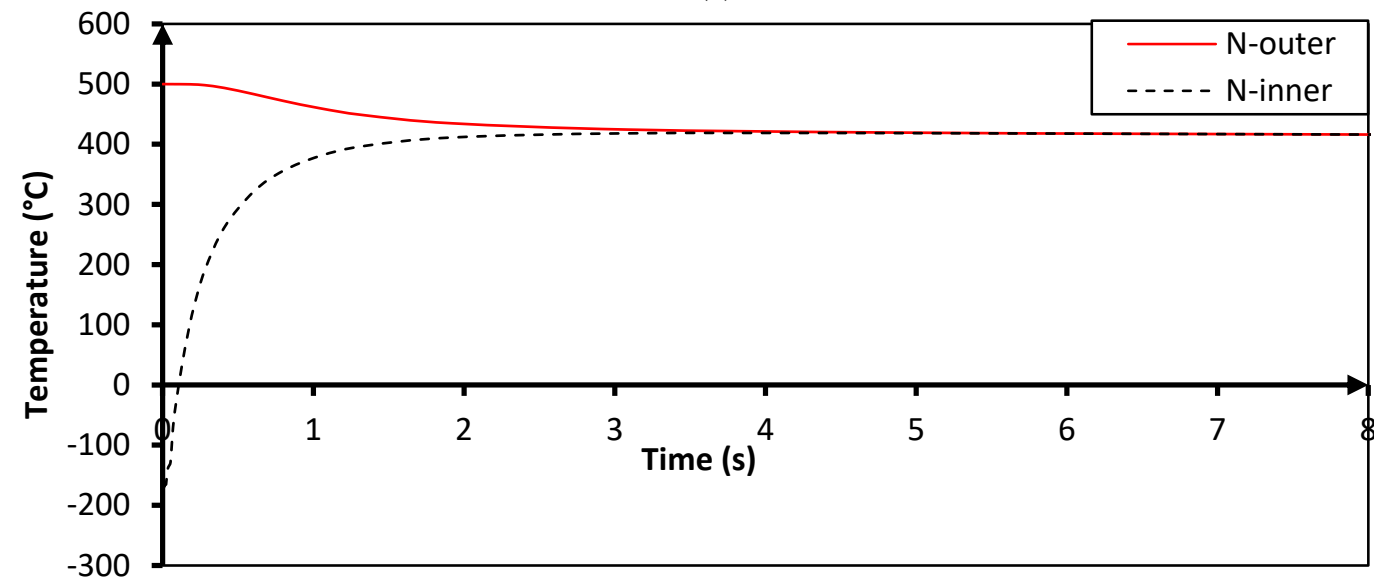

(b)

Fig. 11 Temperature distributions for two points located at $180^{\circ}$ central angle on the inner and outer surfaces (a) through the whole pre-heat treatment and welding (b) through the first seconds of pre-heat treatment.

It is observed that the temperature of the inner point, $\mathrm{N}$-inner, goes up from $-200{ }^{\circ} \mathrm{C}$ to meet the thermal distribution of the outer point, N-outer, at $419^{\circ} \mathrm{C}$ after 4.30 seconds of inserting the liner inside the outer pipe where the initial temperature of the outer point is $500{ }^{\circ} \mathrm{C}$ [27]. It is remarkable that the temperature returns back to room temperature in about 7200 seconds, after which the thermal effect of pre-heat treatment has completely elapsed.

The temperatures computed by the FE model during lined pipe welding and cooling at six points, TC1-TC6, located at the inner and outer surfaces are compared with the ones measured by thermocouples at $180^{\circ}$ central angle along the axial direction as depicted in Fig. 12(a)-(f).

In general, the experimental thermal results are lower than those predicted by the FE model for many reasons. The most important ones are related to the extrapolated materials properties at high temperatures. Also, the experimental results are affected by some specific 
factors, often called 5M1E (Man, Machines, Materials, Methods, Measurements and Environment), which have a significant influence on the quality of welding measures [28]. Overall, the maximum variation between the predicted and measured temperature results is less than $6 \%$ which is reasonably acceptable.

It is noticeable that the cooling rate is relatively larger for higher peak temperatures. It is also observed that points located closer to the welding centreline WCL experience temperatures higher than those located farther away from the WCL. It can be concluded that the thermal analysis of the FE model developed can be considered validated experimentally.

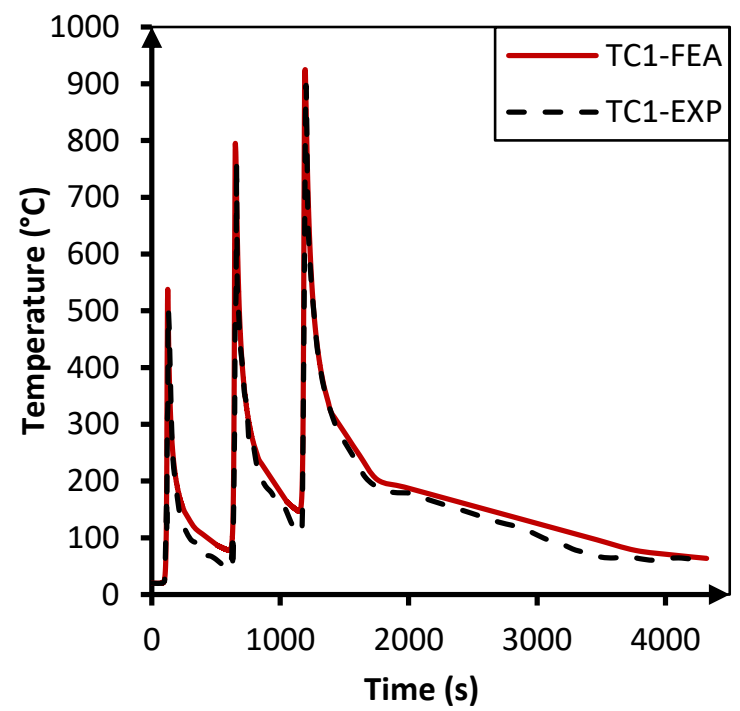

(a)

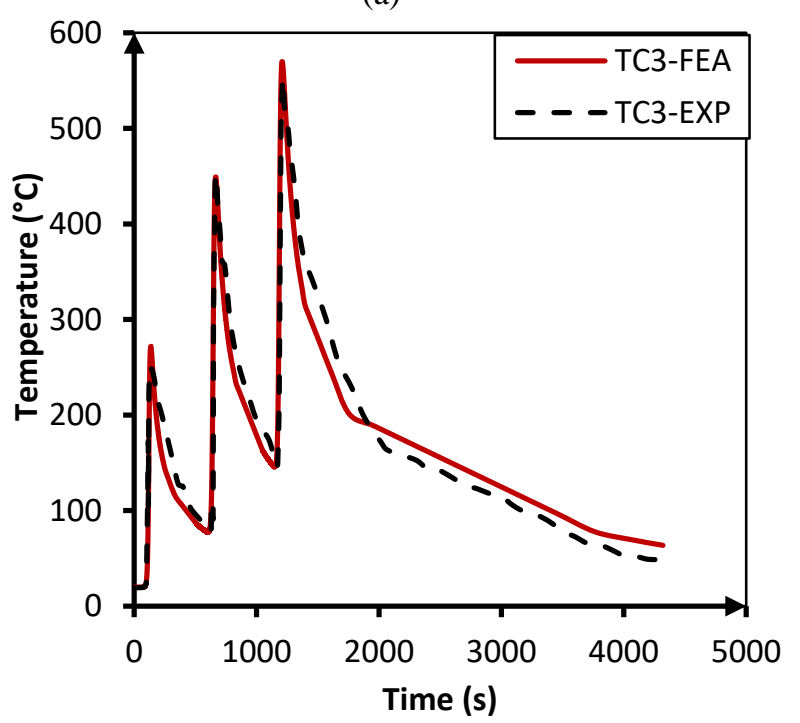

(c)

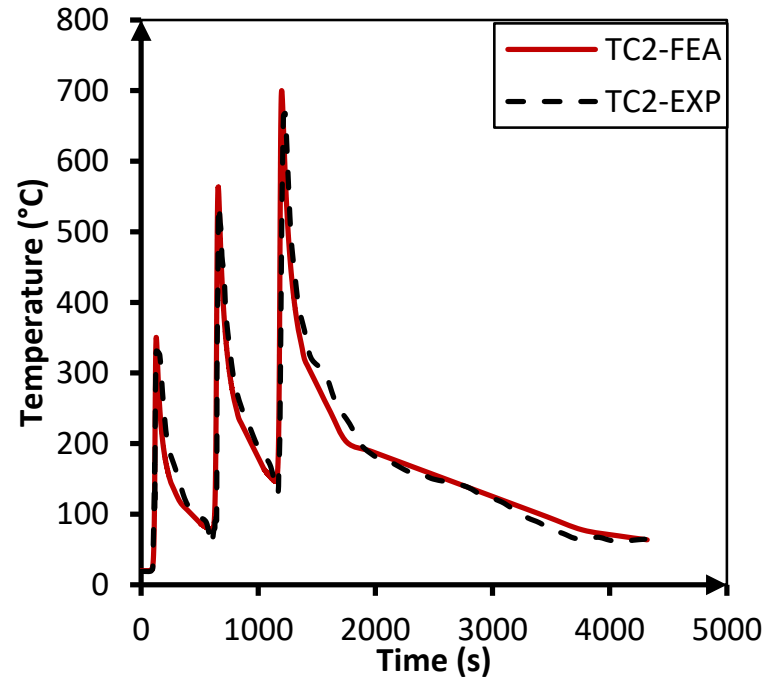

(b)

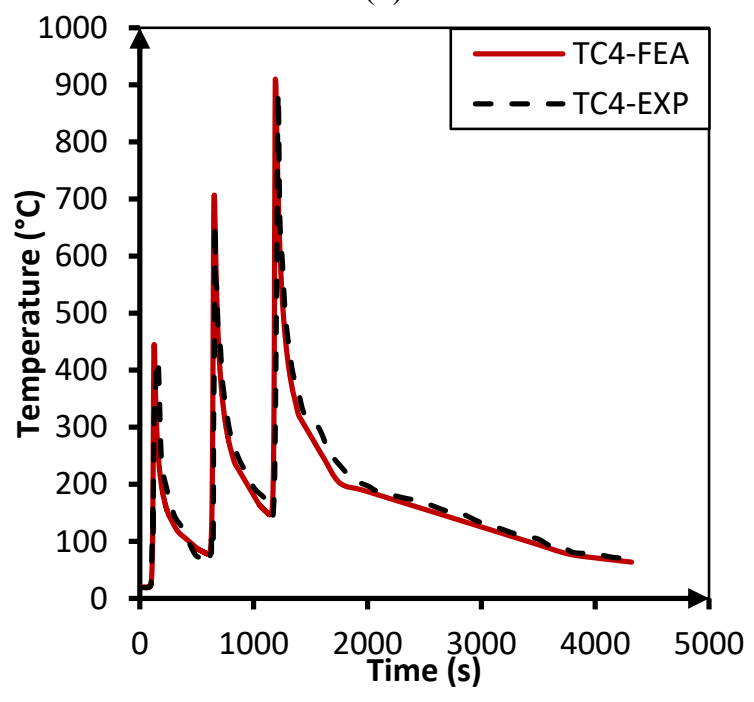

(d) 


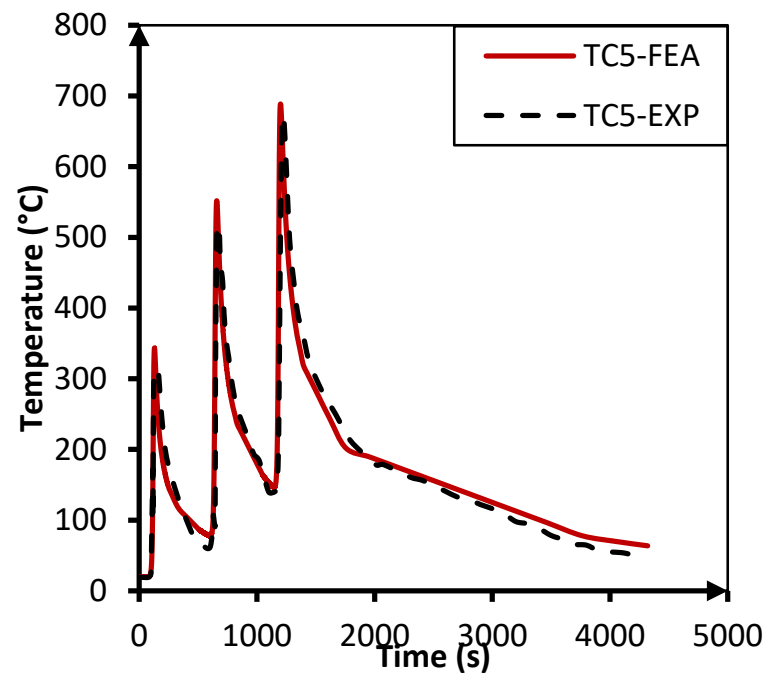

(e)

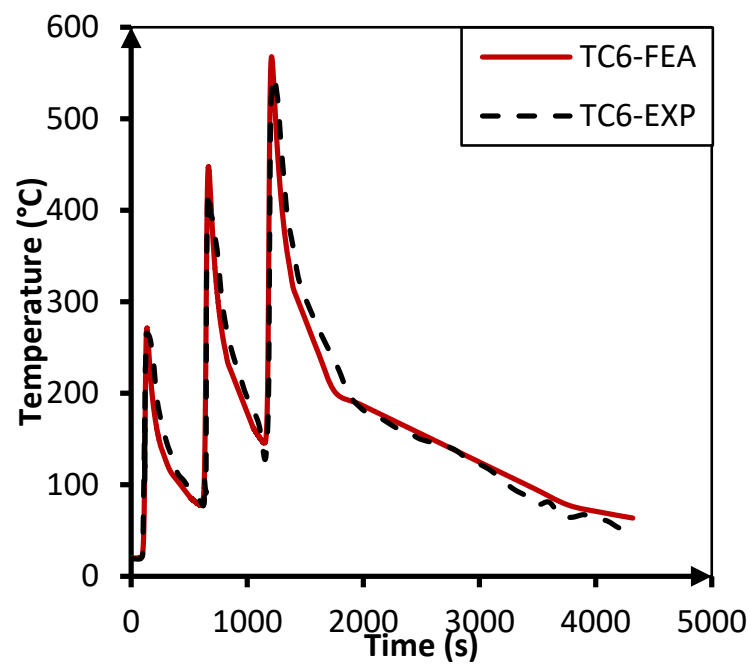

(f)

Fig. 12 Thermal field distributions for thermocouples (a) TC1 (b) TC2 (c) TC3 (d) TC4 (e) TC5 and (f) TC6.

\subsection{Structural response}

\subsubsection{Strain during welding}

Table 4 lists the precise axial and circumferential positions of 12 high temperature strain gauges mounted on the inner and outer surfaces. These strain gauges were accompanied with thermocouples to measure the thermal history at their locations.

The pure transient experimental and numerical mechanical strain distributions without thermal strain effect on the outer and inner surfaces during the welding process are depicted in Figs. 13 and 14, respectively. To measure the thermal strains, two strain gauges were bonded to a piece of C-Mn pipe whilst the other one was attached to a piece of AISI304 pipe. Both pieces were placed in a heating furnace and the strains were set to zero at room temperature. The thermal strains were then recorded as those measured while the temperature increased up to $650^{\circ} \mathrm{C}$, for both materials. In particular, their values were 30 and 40 microstrain at $150^{\circ} \mathrm{C}$ and 360 and 490 micro-strain at $650^{\circ} \mathrm{C}$ for C-Mn and AISI304 materials, respectively. In this way, the mechanical strains have been obtained by deducting the thermal strains from the total ones measured.

It is observed from Figs. 13 and 14, that strain distributions start from zero at the beginning of the weld overlay process in the experiment and case A whereas there are some residual strains in case $\mathrm{AH}$.

During the weld overlay pass, strain gauges record a sudden drop in strains, which become compressive, just before the welding torch is close to the location of the particular gauge. The decrease happens in both directions, axially and circumferentially, on inner and outer surfaces 
with different severity (see for example, Fig. 13(a), gauge A, at 16-35 seconds). The strains in the axial direction decrease more significantly on the inner surface at gauge $G$ than their counterparts on the outer surface at gauges A. The gauges in the circumferential direction on the outer surface, e.g. gauge B, also record a drop in strains lower than those on the inner surface, e.g. gauge $\mathrm{H}$. The reason can be attributed to the increase in pipe radius because of heating near the welding torch.

Once the heat source passes the particular gauge, there is again a remarkably large drop in strain at the axial gauges, e.g. A, after a short increase in strain whilst significant tensile strains are recorded on the inner surface in gauges, e.g. G, Consequently, bending is produced in the pipe because of the shrinkage in the FZ and HAZ due to cooling. Furthermore, strains located in the hoop direction on the inner surface increase gradually before the first girth welding pass starts, see gauge $\mathrm{H}$.

On the outer surface, a remarkable kink in the signals is observed in gauges A and B attributed to the heat coming from the welding area close to the start/stop point. Thus, a small drop in strain happens before the inter-pass time starting at $240 \mathrm{sec}$ (cooling after weld overlay).

During the first girth welding pass, there is, in a similar way, a sudden decrease recorded at all gauges on the inner and outer surfaces because of the approaching heat source. In this process, a smaller decrease in strains have been recorded at the axial locations on the outer surface, e.g. gauge A, compared with the decreases at their counterparts on the inner surface, e.g. gauge G. Likewise in the circumferential direction, a larger decrease in strain is observed on the inner surface when compared with that on the outer surface. Strains in the hoop direction recorded by gauges on the inner and outer surfaces are consistent with the foregoing discussion of the weld overlay.

During the second girth welding, the same behaviour occurs as has been observed during the weld overlay and the first girth welding process. It is noted that the range of decrease in strain due to the approaching heat source is somewhat larger (in absolute terms) than the previous decreases, excluding the gauges which record the axial strains on the outer surface, e.g. gauge A.

During cooling, the transient strain distributions decrease gradually on the outer surface (compressive strains), whilst gradually increasing on the inner surface (tensile strains), 
especially the axial strains. As a result bending occurs in the lined pipe due to the shrinkage of the weld zones.

The forgoing discussion can be applied to the other strain gauges on the outer surface, gauges $\mathrm{C}, \mathrm{D}, \mathrm{E}$ and $\mathrm{F}$, and on the inner surface, gauges I, J, K and L, accordingly. On the outer surface, gauges $\mathrm{C}$ and $\mathrm{E}$ have similar strain behaviour of gauge $\mathrm{A}$ at the axial direction whilst the strain history of gauges $\mathrm{D}$ and $\mathrm{F}$ is analogous to that of gauge $\mathrm{B}$ at the hoop direction. On the inner surface, gauges I and $\mathrm{K}$ at the axial direction have the same strain trend of gauge $\mathrm{G}$ whilst gauges $\mathbf{J}$ and $\mathbf{L}$ have an analogous strain trend. In general, the numerically computed transient strain curves allowing for pre-heat treatment, case $\mathrm{AH}$, correlate well with those of case A during welding at all axial and circumferential gauges on the inner and outer surfaces. Consequently, the deviations in strains between cases A and $\mathrm{AH}$ are very small and can be ignored during welding at all locations because the high temperatures lead to the removal of the effect of pre-heat treatment residual stresses at the FZ and its vicinity. Furthermore, it is observed that there is very good agreement between numerical results in case A and case $\mathrm{AH}$ and the experimental results.

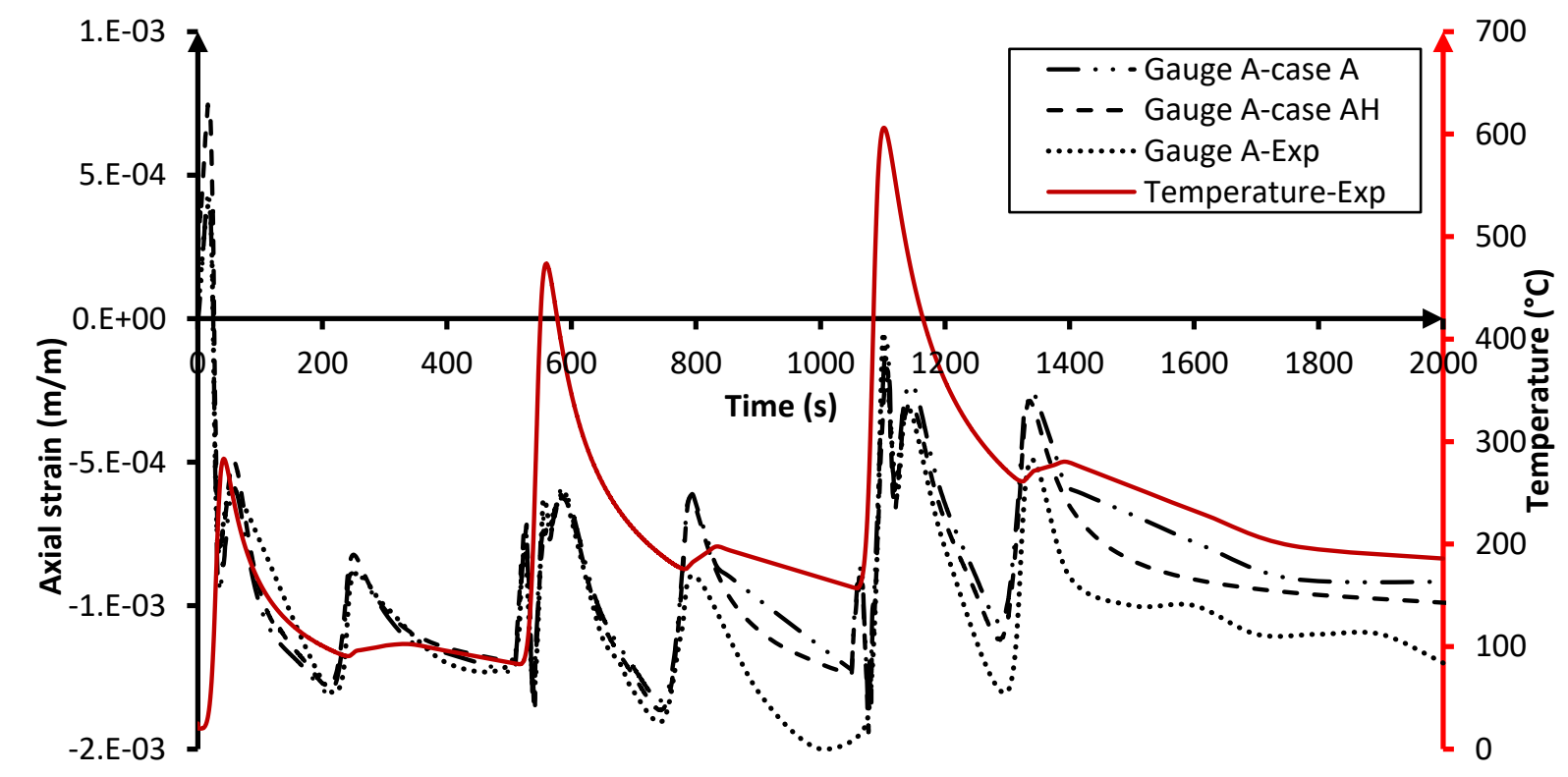

(a) 


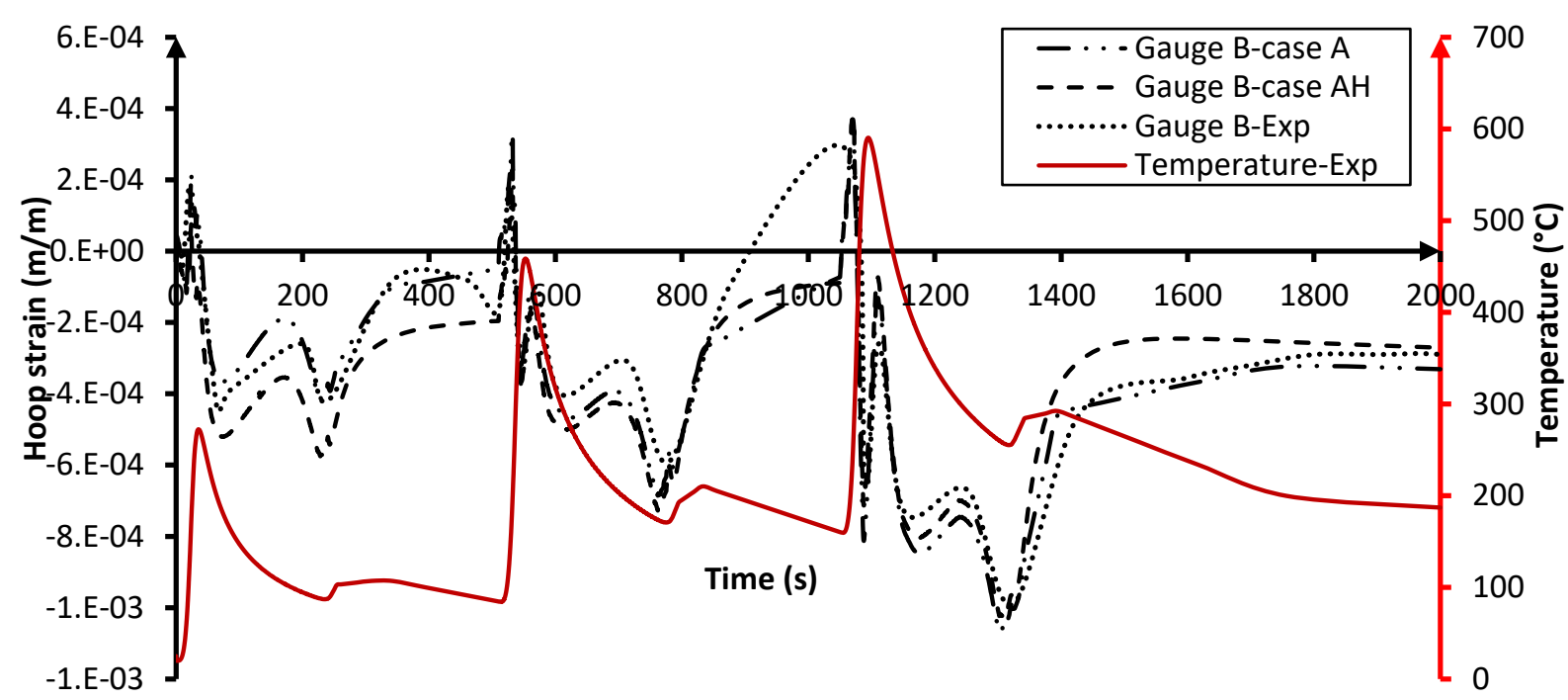

(b)

Fig. 13 Mechanical strain history during welding associated with thermal history on the outer surface for (a) gauge A and (b) gauge B.

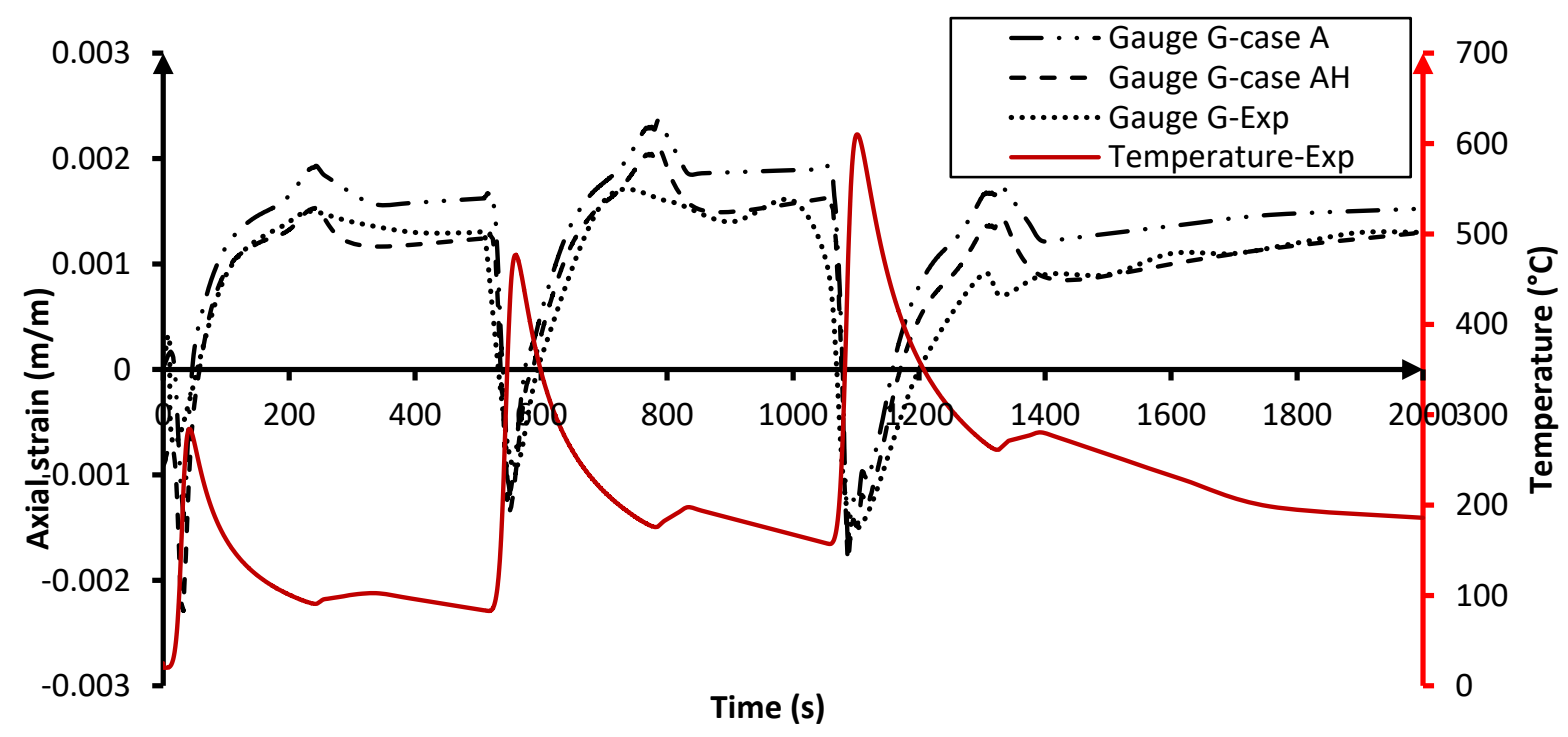

(a)

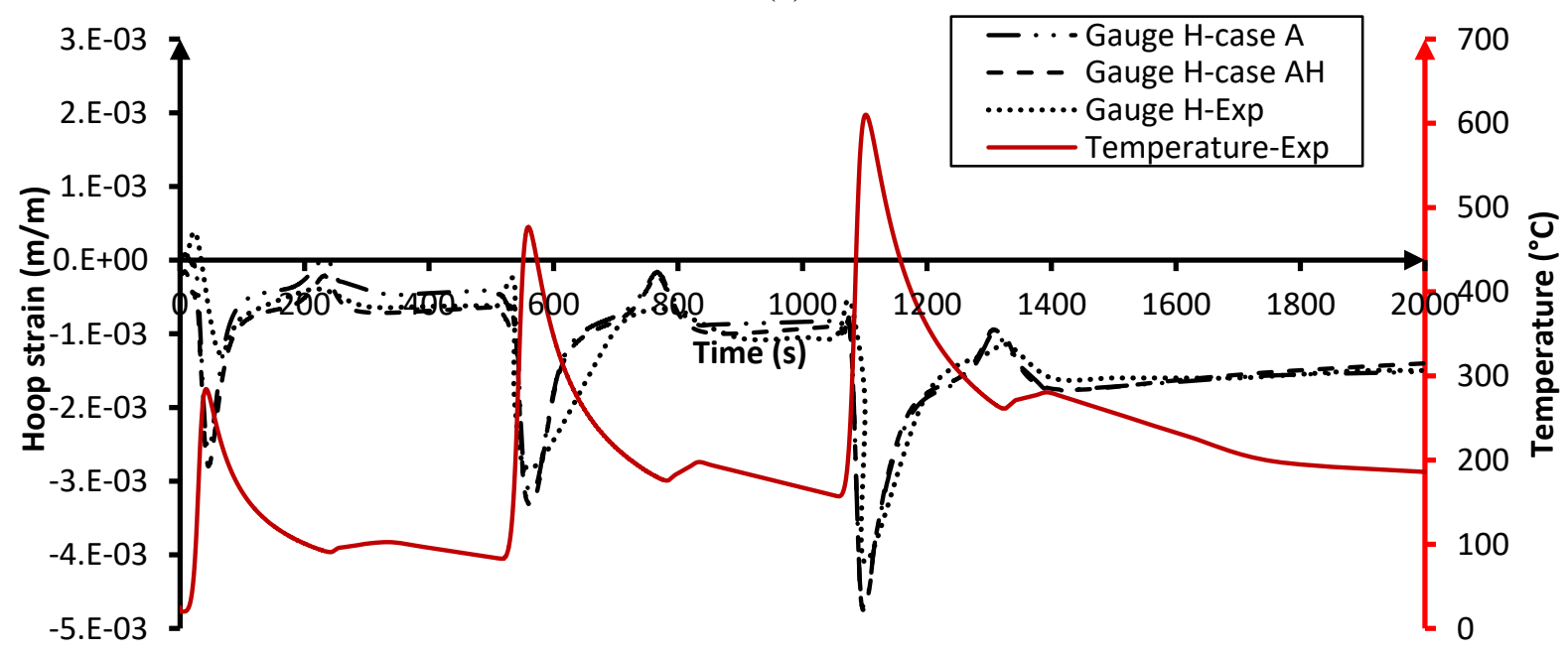

(b) 
Fig. 14 Mechanical strain history during welding associated with thermal history on the inner surface for (a) gauge $\mathrm{G}$ and (b) gauge $\mathrm{H}$.

\section{Residual stress and plastic deformation}

\subsection{Residual stresses on the inner surface}

The numerically predicted axial and hoop residual stress distributions on the inner surface, which is made of AISI304 stainless steel, for the two cases are compared in Figs. 13 and 14 with the experimental results obtained from residual strain gauges at the $180^{\circ}$ central angle from the start/stop welding position.

From Fig. 15, it is observed that the peak values of both the experimentally measured residual axial stress and the numerically computed one are at the WCL $(\mathrm{Z}=0)$. This point is at the toe of the girth welding, which is filled with girth welding material and extends up to a distance of $0.6 \mathrm{~mm}$ from the WCL. In contrast, Fig. 16 shows that the peak value of the numerically predicted hoop tensile stresses is located within the FZ of the weld overlay, at a distance of about $2.1 \mathrm{~mm}$ from the WCL. At the WCL, the peak values of the computed axial and hoop stresses are 606 and $450 \mathrm{MPa}$, respectively, for both case A and case AH. The experimentally measured values of the axial and hoop residual stresses at the WCL are 585 and $480 \mathrm{MPa}$, respectively.

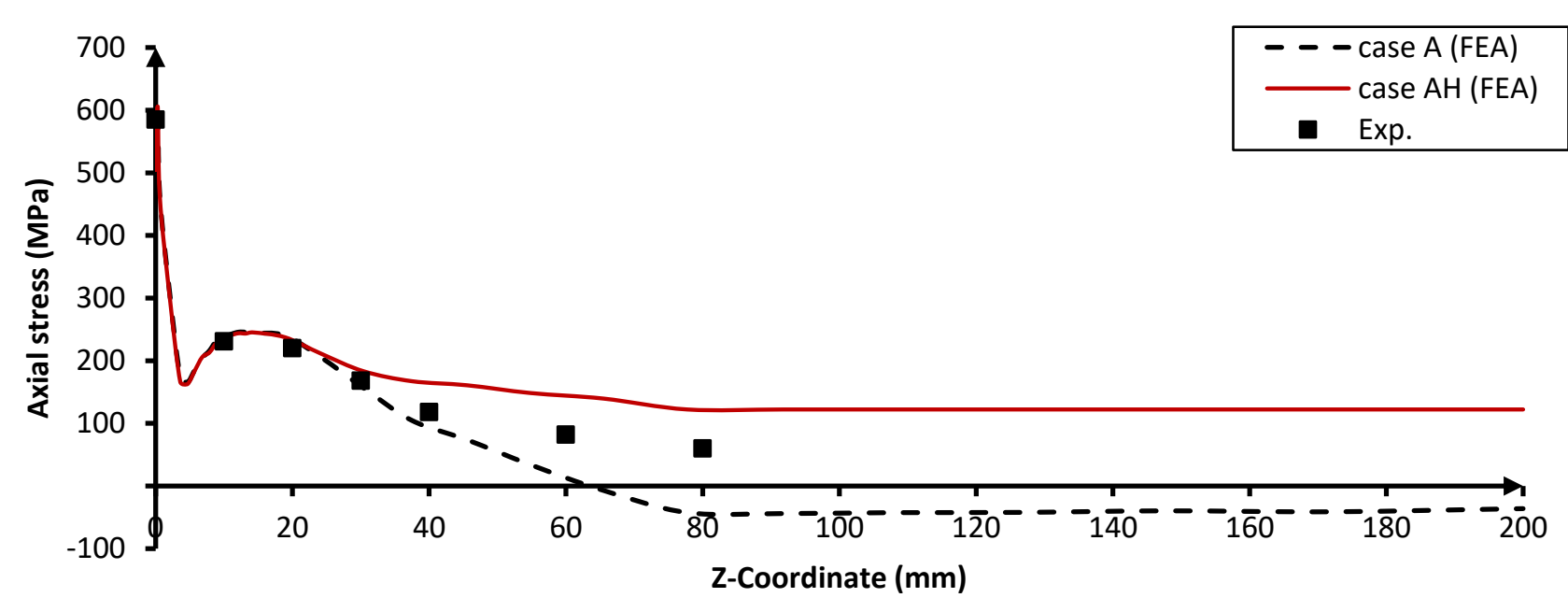

Fig. 15 Axial residual stress at $180^{\circ}$ central angle on the inner surface, AISI304 pipe, against axial distance. 


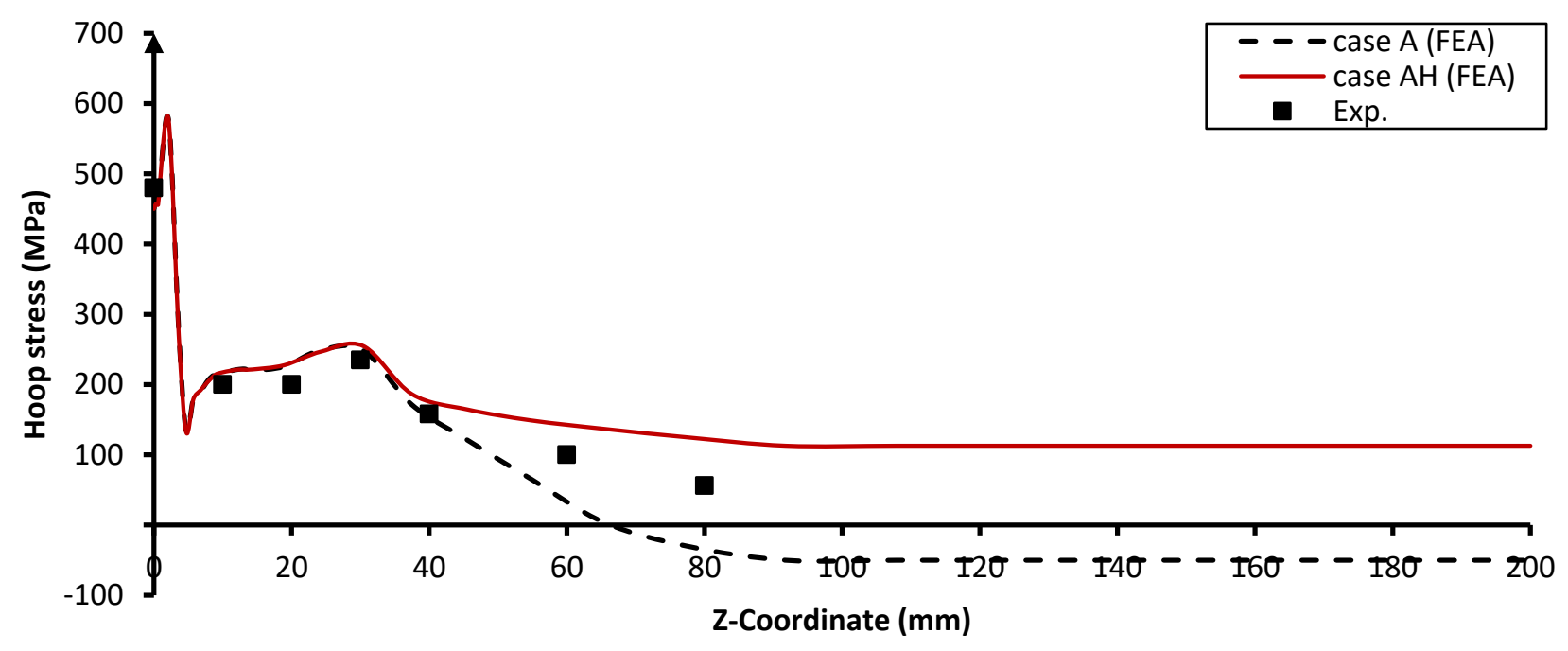

Fig. 16 Hoop residual stress at $180^{\circ}$ central angle on the inner surface, AISI304 pipe, against axial distance.

From Fig. 16, it is observed that the peak computed values of the residual hoop stress, 578 $\mathrm{MPa}$, is attained in both cases at a distance of about $2.1 \mathrm{~mm}$ from the WCL at the centre of the FZ of the weld overlay where the heat source is applied.

From Fig. 15, we can also find out that the numerically predicted residual axial stresses for cases $\mathrm{A}$ and $\mathrm{AH}$ are identical up to a distance of about $24 \mathrm{~mm}$ from the WCL. From this point, they deviate and reach a maximum difference at a distance of about $77 \mathrm{~mm}$ from the WCL. This difference then remains constant and equal to $164 \mathrm{MPa}$. Likewise, from Fig. 16, it is observed that the hoop residual stresses computed for the two cases are identical up to a distance of $37 \mathrm{~mm}$ from the WCL. From this point, they deviate and reach a maximum difference at a distance of about $91 \mathrm{~mm}$ from the WCL. This difference then remains constant and equal to $162 \mathrm{MPa}$.

For both the axial and the hoop stresses, the experimental measurements are in excellent agreement with the computed values in the ranges where they are identical. Where results differ between cases $\mathrm{A}$ and $\mathrm{AH}$, the experimental measurements are located between the numerically predicted distributions for the two cases.

It can be concluded that, in the zone where results computed for cases $\mathrm{A}$ and $\mathrm{AH}$ coincide, which include the FZ and the HAZ, there is no influence of the pre-heat treatment. From the point where results start differing between the two cases, the pre-heat treatment affects the residual stresses and the experimental results are located between the numerically predicted distributions for the two cases.

This can be explained because the FZ and HAZ are heated up to temperatures much higher than other areas, which significantly softens the base material AISI304. Consequently, the 
inherent residual stresses, which existed in the base material because of the heat treatment, are removed completely. Thus, the residual stress distributions in case AH coincide with those for case A at the inner surface. Beyond a distance of about $24 \mathrm{~mm}$ from the WCL, temperatures during welding are much lower and their effect disappears completely at a distance greater than $91 \mathrm{~mm}$.

\subsection{Residual stresses on the outer surface}

Fig. 17 shows the axial residual stress distributions on the outer surface, which is made of CMn steel, along the axial direction of the lined pipe at $180^{\circ}$ (central angle) for cases $\mathrm{A}, \mathrm{AH}$ and the experimental results. As with the residual stresses on the inner surface, there is a good correlation between the results of case A and case $\mathrm{AH}$ at the FZ and HAZ within a distance of about $24 \mathrm{~mm}$ from the WCL. Beyond this limit, a slight deviation occurs between two cases, but then the results intersect again before reaching a constant value. Beyond a distance of about $77 \mathrm{~mm}$ from the WCL, the difference between the axial residual stress distributions keeps to a large extent constant for case A and case AH. The experimental results are in good agreement with two cases.

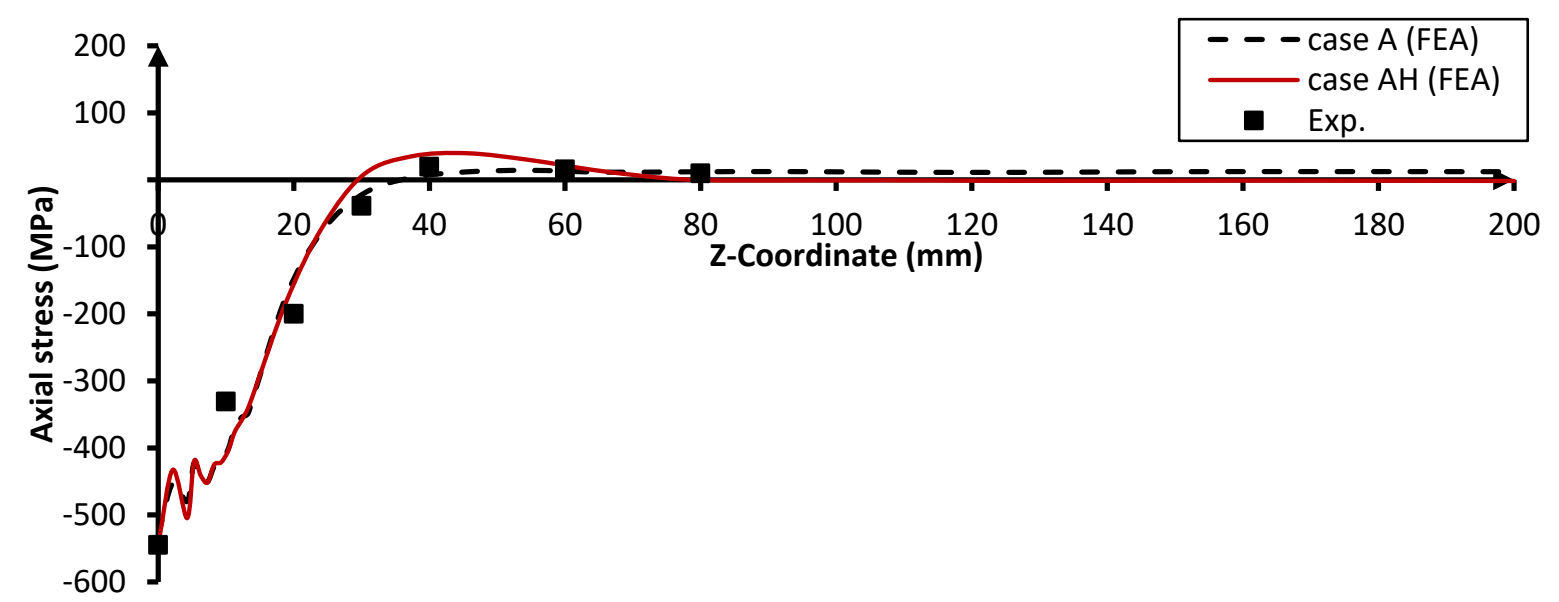

Fig. 17 Axial residual stress at $180^{\circ}$ central angle on the outer surface, C-Mn pipe, along the axial direction.

The same arguments can be applied to the hoop residual stress distributions in cases A and $\mathrm{AH}$ on the outer surface at $180^{\circ}$ from the start/stop welding location as depicted in Fig. 18. The two distributions slightly deviate at a distance of about $37 \mathrm{~mm}$ from the WCL. Beyond a distance of about $91 \mathrm{~mm}$, the case A distribution is stable with zero stress and case $\mathrm{AH}$ distribution is stable with a slightly positive stress. The experimental results are again in good agreement with both distributions. 


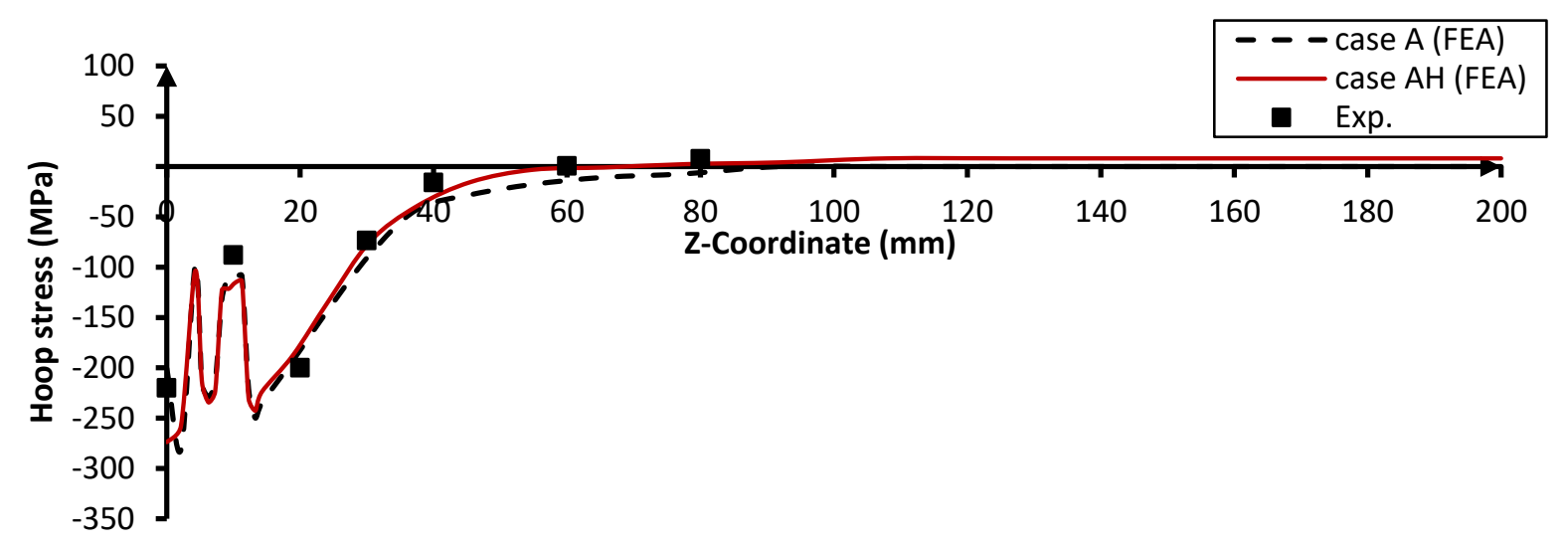

Fig. 18 Hoop residual stress at $180^{\circ}$ central angle on the outer surface, C-Mn, along the axial direction.

\section{Verification of the experimental results}

To check the accuracy of experimental thermal and mechanical results, the welding test was repeated, with the same conditions both times. The thermocouples and residual stress gauges using were placed at the same locations for both tests. To double check the reliability of residual stress results, X-ray diffraction (XRD) has also been used for the first test. The Xrays were generated by a cathode ray tube $(\mathrm{Cr}-\mathrm{K} \alpha 1$ tube), filtered to produce monochromatic radiation, collimated to concentrate $(1 \mathrm{~mm})$, and directed toward the sample with a diffraction angle $\left(2 \theta=156^{\circ}\right)$. A Bruker D8 Advance X-ray diffractometer instrument has been used to achieve that. The used XRD measures residual stresses for a particular point located very near the surface (within few tens of microns). As a result, the residual stresses can be mapped along the FZ, HAZ and base materials on the outer surface (C-Mn pipe) and the inner surface (AISI304 pipe).

Fig. 19 compares the thermal history recorded from TC1 for two tests at $180^{\circ}$ central angle. It can be noticed that the peak temperatures and cooling rates are extremely similar.

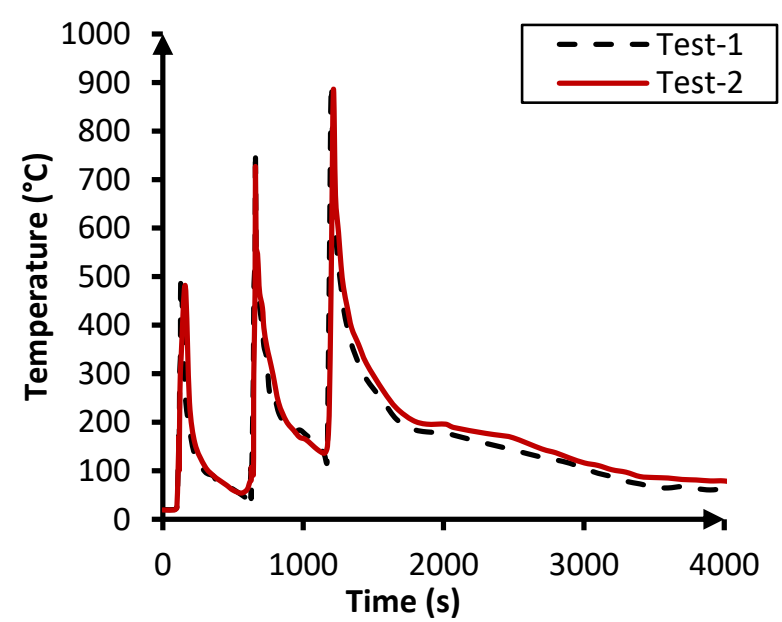

Fig. 19 Measured temperature results of repeated tests at $\mathrm{TC} 1$ at $180^{\circ}$ central angle. 
Fig. 20 shows the axial residual stresses on the inner surface obtained by the hole-drilling technique using residual stress gauges, FRS-2, for two tests. Also, the residual stress results of XRD for the first test are plotted in the same figure. It can be observed that all results in the first test are consistent with their counterparts in the second one and the results of XRD prove the reliability of the experimental residual stress results.

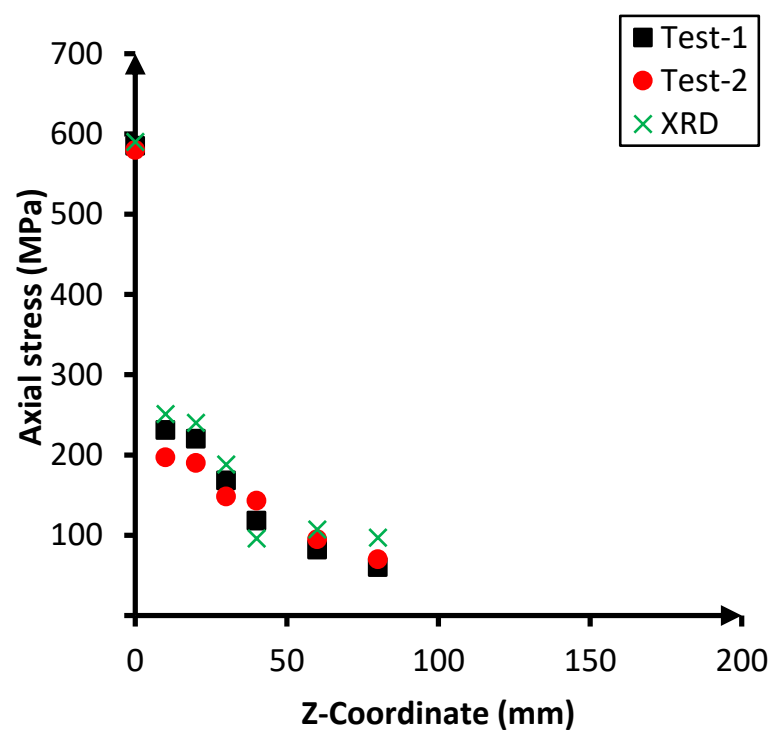

Fig. 20 Experimental axial residual stress results of repeated tests on the inner surface at $180^{\circ}$ central angle.

\section{Mesh convergence analysis}

The FE mesh density plays a key role in determining the accuracy of numerical results. For accurate FE welding analysis, a fine mesh is required at regions in which bending takes place [29]. In other words, increasing the mesh size of applied heat source elements leads to increase the temperature over the targeted one because of the overestimation of central heat input [30]. To assess such accuracy, a coarse mesh analysis has been used for both the thermal and the mechanical analyses for case A. The coarse mesh model consists of 14000 nodes associated with 2880 elements. The element type is DC3D20 and C3D20 in the thermal and mechanical analyses in ABAQUS, respectively. Also, the element birth technique is adopted in the FEM coarse model to simulate depositing the filler materials in the weld overlay and girth welding while moving the heat source. The coarse mesh size is equal to or larger than 1.5 times the normal mesh size utilized in this study for case A (see Fig. 5) with the coarse mesh model being composed of 40 circumferential elements instead of 60 elements, as shown in Fig. 21. 


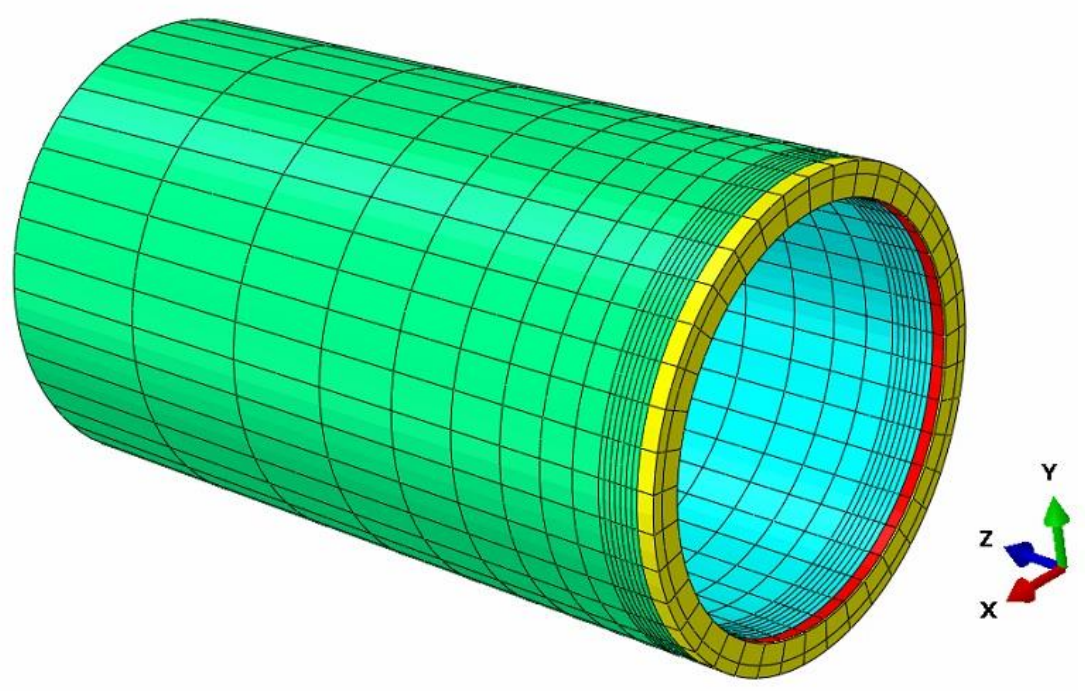

Fig. 21 Coarse 3-D FE model (case A)

In the thermal analysis, Fig. 22 compares the temperature distributions during the second pass of girth welding for the coarse mesh model, denoted as $1.5 \mathrm{~h}$, against the normal mesh model, denoted as $1 \mathrm{~h}$, at $90^{\circ}, 180^{\circ}$ and $270^{\circ}$ central angle. The maximum temperature is achieved at the WCL which is $2085^{\circ} \mathrm{C}$ in the coarse mesh model and $2076^{\circ} \mathrm{C}$ in the normal mesh model of case A.

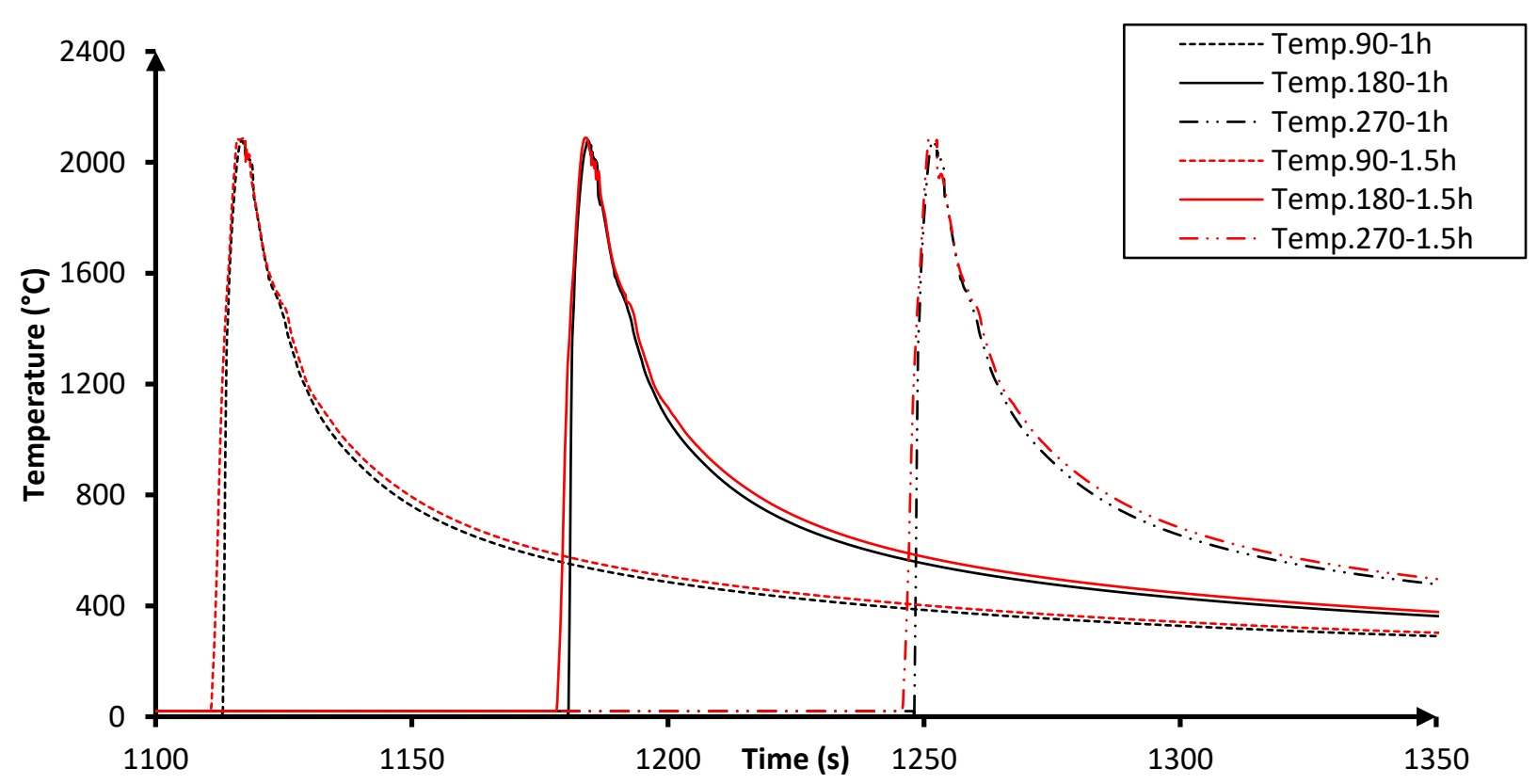

Fig. 22 The thermal history of second pass centre of girth welding at $90^{\circ}, 180^{\circ}$ and $270^{\circ}$ central angle for coarse and normal mesh.

One may note that there is a very good correlation in the thermal fields between the coarse mesh and the normal mesh models. As a consequence of thermal correlation, the residual stress distributions on the inner and outer surfaces for the coarse mesh model should also be consistent with the results of the normal mesh model of case A. Fig. 23 plots the axial 
residual stress distributions comparisons between the coarse mesh model and the normal mesh model at $180^{\circ}$ central angle on the inner surface.

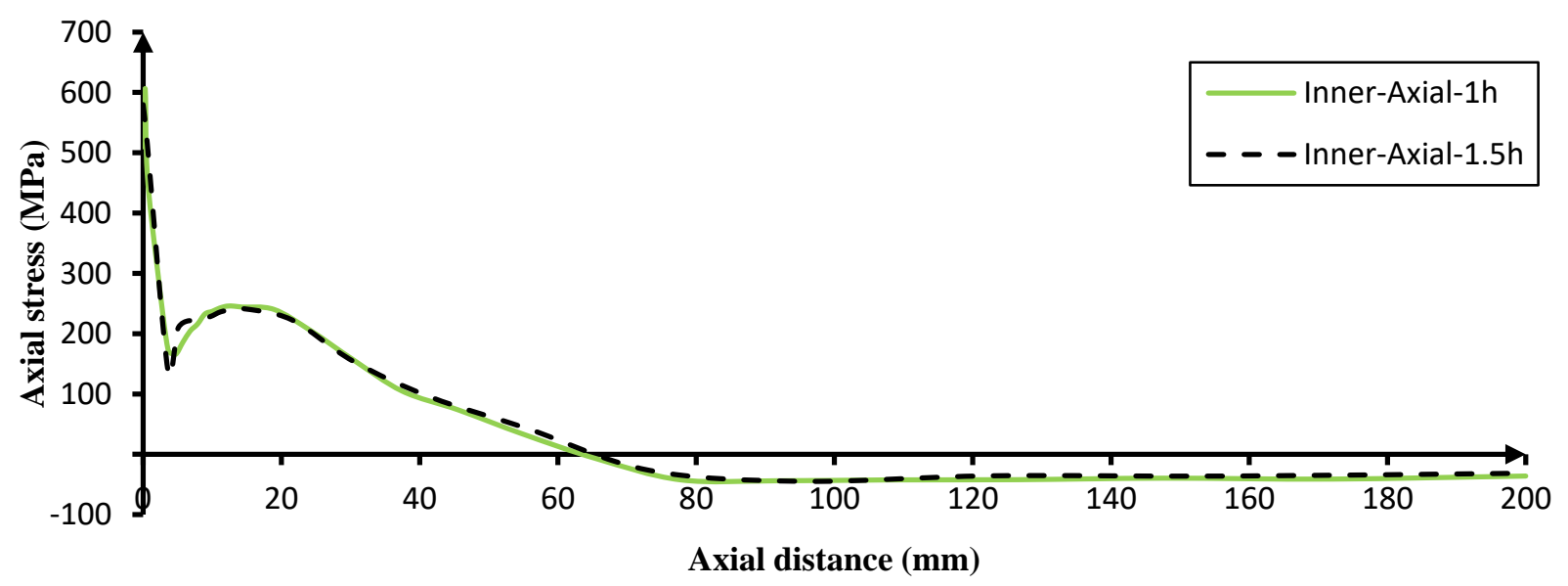

Fig. 23 Axial residual stress distributions for coarse and normal mesh models at $180^{\circ}$ central angle on the inner surface.

Consequently, the normal mesh used in cases A and AH can be considered appropriate to obtain accurate numerical results thermally and mechanically.

\section{Conclusions}

This study has consisted of 3D FE thermo-mechanical simulations of the welding process of a lined pipe, executed using ABAQUS, and it has compared numerical data with experimental results. The study included an investigation of the effect of pre-heat treatment on thermal fields and residual stresses. To produce the lined pipe, the Tight Fit Pipe process is essential for inserting the liner (AISI304 pipe) inside the backing pipe (C-Mn pipe). The initial residual stress levels generated by the TFP are based on the temperature levels and the mechanical properties of both base materials. In this work, the numerical and experimental results have proved that the initial residual stresses due of TFP are important in the AISI304 pipe whereas they hardly existed in the C-Mn pipe. According to the numerical and experimental results in this work, the following conclusions can be drawn:

(1) Based on the thermal results, it is clear that the temperatures of all points located on the same circumferential line are the same when the welding torch moves to fill the weld overlay and during the girth welding. From the outcomes of our investigation, it is possible to conclude that the temperature fields are not sensitive to the variations of the circumferential angles. Furthermore, the thermal history during welding is not affected by the TFP process because the temperature returns to room temperature after natural cooling for 7200 seconds. 
(2) The high temperature strain gauges on the inner surface record a larger drop in the axial and hoop strains just before the welding torch is close to the location of the particular gauge than at their counterparts on the outer surface during both the weld overlay, and the first and second girth welding. This can be attributed to the increase in pipe radius because of heating near the welding torch.

(3) The residual stress distributions can be divided into three sections. In the first one, close to the WCL, the residual stresses are solely affected by the welding process. The length of this zone depends on the extent of the axial and hoop plastic strains. The second zone stretches from the previous one to the limit where the residual stress distributions become constant along the length. This section is under the influence of both the welding process and the TFP pre-heat treatment. The last section starts when the residual stress distribution has become quite constant, in which the pipe is just under the influence of the initial residual stresses resulting from the TFP process. The initial residual stresses are relatively small in the AISI304 pipe whilst they are negligible in the C-Mn pipe.

(4) Welding tests with thermal and mechanical measurements have been repeated. Due to the importance of residual stresses, X-ray diffraction has been used to double check the residual results obtained by residual strain gauges. All thermal and mechanical results from the first test are consistent with their counterparts in the second test.

\section{Acknowledgments}

The authors would like to thank all the lab technicians, and in particular Mr Paul Yates and Mr Guy Fitch, for their help and technical advice during the experimental work conducted at Brunel University, as well as Dr Lorna Anguilano for her assistance on XRD measurements.

\section{References}

[1] Obeid, O., Alfano, G. and Bahai, H., 2014. Analysis of the temperature evolution during lined pipe welding. In Advanced Materials Research (Vol. 1016, pp. 753-757). Trans Tech Publications.

[2] Fu, A.Q., Kuang, X.R., Han, Y., Lu, C.H., Bai, Z.Q., Yin, C.X., Miao, J., Feng, Y.R., Wei, Y.G., Tang, Q. and Yang, Y., 2016. Failure analysis of girth weld cracking of mechanically lined pipe used in gasfield gathering system. Engineering Failure Analysis, 68, pp.64-75.

[3] Bate, S. and Smith, M., 2016. Determination of residual stresses in welded components by finite element analysis. Materials Science and Technology, 32(14), pp.1505-1516.

[4] Karlsson, R. I., \& Josefson, B. L. (1990). Three-dimensional finite element analysis of temperatures and stresses in a single-pass butt-welded pipe. Journal of pressure vessel technology, 112(1), 76-84. 
[5] Jonsson, M., \& Josefson, B. L. (1988). Experimentally determined transient and residual stresses in a buttwelded pipe. The Journal of Strain Analysis for Engineering Design, 23(1), 25-31.

[6] Josefson, L., Jonsson, M., Karlsson, L., Karlsson, R., Karlsson, T., \& Lindgren, L. E. (1989, January). Transient and residual stresses in a single-pass butt welded pipe. In International Conference on Residual Stresses (pp. 497-503). Springer Netherlands.

[7] Karlsson, C. T. (1989). Finite element analysis of temperatures and stresses in a single-pass butt-welded pipe-influence of mesh density and material modelling. Engineering computations, 6(2), 133-141.

[8] Brickstad, B., \& Josefson, B. L. (1998). A parametric study of residual stresses in multi-pass butt-welded stainless steel pipes. International Journal of Pressure Vessels and Piping, 75(1), 11-25.

[9] Deng, D. and Murakawa, H. (2006) 'Numerical simulation of temperature field and residual stress in multipass welds in stainless steel pipe and comparison with experimental measurements', Computational materials science, 37(3), pp. 269-277.

[10] Zhao, L., Liang, J., Zhong, Q., Yang, C., Sun, B. and Du, J., 2014. Numerical simulation on the effect of welding parameters on welding residual stresses in T92/S30432 dissimilar welded pipe. Advances in Engineering Software, 68, pp.70-79.

[11] Huang, H., Wang, J., Li, L. and Ma, N., 2016. Prediction of laser welding induced deformation in thin sheets by efficient numerical modeling. Journal of Materials Processing Technology, 227, pp.117-128.

[12] Manvatkar, V., De, A. and DebRoy, T., 2014. Heat transfer and material flow during laser assisted multilayer additive manufacturing. Journal of Applied Physics, 116(12), p.124905.

[13] Mukherjee, T., Zhang, W. and DebRoy, T., 2017. An improved prediction of residual stresses and distortion in additive manufacturing. Computational Materials Science, 126, pp.360-372.

[14] Deng, D., Kiyoshima, S., Ogawa, K., Yanagida, N., \& Saito, K. (2011). Predicting welding residual stresses in a dissimilar metal girth welded pipe using 3D finite element model with a simplified heat source. Nuclear Engineering and Design, 241(1), 46-54.

[15] Obeid, O., Alfano, G. and Bahai, H., 2017. Thermo-Mechanical Analysis of a Single-Pass Weld Overlay and Girth Welding in Lined Pipe. Journal of Materials Engineering and Performance, 26(8), pp.3861-3876.

[16] Obeid, O., Alfano, G., Bahai, H. and Jouhara, H., 2017. Numerical simulation of thermal and residual stress fields induced by lined pipe welding. Thermal Science and Engineering Progress.

[17] Obeid, O., Alfano, G., Bahai, H. and Jouhara, H., 2017. A parametric study of thermal and residual stress fields in lined pipe welding. Thermal Science and Engineering Progress.

[18] McHenry, H.I., 1983. The properties of austenitic stainless steel at cryogenic temperatures. Austenitic Steels at Low Temperature, pp.1-28.

[19] Focke, E.S., 2007. Reeling of tight fit pipe. TU Delft, Delft University of Technology.

[20] Vasilikis, D. and Karamanos, S.A., 2012. Mechanical behavior and wrinkling of lined pipes. International Journal of Solids and Structures, 49(23), pp.3432-3446.

[21] Brennan, F. and Tavares, I., 2014. Fatigue design of offshore steel mono-pile wind substructures. Proceedings of the Institution of Civil Engineers-Energy, 167(4), pp.196-202.

[22] ABAQUS Documentation, release 14. Dassault Syste`mes, Providence, RI.

[23] Deng, D., 2009. FEM prediction of welding residual stress and distortion in carbon steel considering phase transformation effects. Materials \& Design, 30(2), pp.359-366. 
[24] Yaghi, A.H., Hyde, T.H., Becker, A.A., Sun, W., Hilson, G., Simandjuntak, S., Flewitt, P.E.J., Pavier, M.J. and Smith, D.J., 2010. A comparison between measured and modeled residual stresses in a circumferentially butt-welded P91 steel pipe. Journal of Pressure Vessel Technology, 132(1), p.011206.

[25] Deng, D., Murakawa, H. and Liang, W. (2008) 'Numerical and experimental investigations on welding residual stress in multi-pass butt-welded austenitic stainless steel pipe', Computational Materials Science, 42(2), pp. 234-244.

[26] Malik, A.M., Qureshi, E.M., Dar, N.U. and Khan, I. (2008) 'Analysis of circumferentially arc welded thinwalled cylinders to investigate the residual stress fields', Thin-Walled Structures, 46(12), pp. 1391-1401.

[27] Obeid, O., Alfano, G., Bahai, H. and Jouhara, H., 2018. Mechanical response of a lined pipe under dynamic impact. Engineering Failure Analysis.

[28] Zhou, X. and Jiang, P., 2017. Variation source identification for deep hole boring process of cutting-hard workpiece based on multi-source information fusion using evidence theory. Journal of Intelligent Manufacturing, 28(2), pp.255-270.

[29] Schenk, T., Richardson, I.M., Kraska, M. and Ohnimus, S., 2009. Modeling buckling distortion of DP600 overlap joints due to gas metal arc welding and the influence of the mesh density. Computational Materials Science, 46(4), pp.977-986.

[30] Huang, H., Tsutsumi, S., Wang, J., Li, L. and Murakawa, H., 2017. High performance computation of residual stress and distortion in laser welded 301L stainless sheets. Finite Elements in Analysis and Design, 135, pp.1-10. 